\title{
Febre amarela
}

\author{
Yellow fever
}

\section{Pedro Fernando da Costa Vasconcelos ${ }^{1}$}

Resumo A febre amarela é doenca infecciosa não-contagiosa causada por um arbovírus mantido em ciclos silvestres em que macacos atuam como hospedeiros amplificadores e mosquitos dos gêneros Aedes na África, e Haemagogus e Sabethes na América, são os transmissores. Cerca de $90 \%$ dos casos da doença apresentam-se com formas clínicas benignas que evoluem para a cura, enquanto $10 \%$ desenvolvem quadros dramáticos com mortalidade em torno de $50 \%$. O problema mostra-se mais grave em África onde ainda há casos urbanos. Nas Américas, no período de 1970-2001, descreveram-se 4.543 casos. Os países que mais diagnosticaram a doença foram o Peru (51,5\%), a Bolívia (20,1\%) e o Brasil (18,7\%). Os métodos diagnósticos utilizados incluem a sorologia (IgM), isolamento viral, imunohistoquímica e RT-PCR. A zoonose não pode ser erradicada, mas, a doença humana é prevenível mediante a vacinação com a amostra 17D do vírus amarílico. A OMS recomenda nova vacinação a cada 10 anos. Neste artigo são revistos os principais conceitos da doença e os casos de mortes associados à vacina.

Palavras-chaves: Febre amarela. Icterícia. Vacina. Aedes. Hepatite.

Abstract Yellow fever is an infectious and non-contagious disease caused by an arbovirus, the yellow fever virus. The agent is maintained in jungle cycles among primates as vertebrate hosts and mosquitoes, especially Aedes in Africa, and Haemagogus and Sabethes in America. Approximately $90 \%$ of the infections are mild or asymptomatic, while $10 \%$ course to a severe clinical picture with $50 \%$ case-fatality rate. Yellow fever is largely distributed in Africa where urban epidemics are still reported. In South America, between 1970-2001, 4,543 cases were reported, mostly from Peru (51.5\%), Bolivia (20.1\%) and Brazil (18.7\%). The disease is diagnosed by serology (detection of IgM), virus isolation, immunohistochemistry and RT-PCR. Yellow fever is a zoonosis and cannot be eradicated, but it is preventable in man by using the 17D vaccine. A single dose is enough to protect an individual for at least 10 years, after which revaccination is recommended. In this paper, the main concepts about yellow fever as well as the fatal adverse effects of the vaccine are updated.

Key-words: Yellow fever. Jaundice. Vaccine. Aedes. Hepatitis.

A febre amarela é uma doença infecciosa não contagiosa que se mantém endêmica ou enzoótica nas florestas tropicais da América e África causando periodicamente surtos isolados ou epidemias de maior ou menor impacto em saúde pública, sendo transmitida ao homem mediante a picada de insetos hematófagos da família Culicidae, em especial dos gêneros Aedes e Haemagogus $^{31}{ }^{52}$. Em África, também tem sido registrado o isolamento viral a partir de carrapatos Amblyoma variegatum, em áreas secas, o que pode indicar o papel secundário desses insetos na cadeia de transmissão da virose em que se demonstrou transmissão transovariana e para macacos ${ }^{67}$.

Insere-se o vírus da febre amarela no grupo dos arbovírus (do inglês arthropod borne virus) e ele apresenta-se em sua forma clássica com febre hemorrágica de elevada letalidade. A febre amarela constitui a febre hemorrágica viral original, a primeira descrita no mundo, a que mais temor provoca na sociedade moderna ${ }^{3152}$.

Sob o ponto de vista epidemiológico divide-se a febre amarela em duas formas, rural e urbana que diferem

1. Centro Colaborador da Organização Mundial de Saúde para Arbovírus do Instituto Evandro Chagas da Fundação Nacional de Saúde (FUNASA) do Ministério da Saúde, Belém, PA.

Endereço para correspondência: Dr. Pedro Fernando da Costa Vasconcelos. Instituto Evandro Chagas/FIOCRUZ. Av. Almirante Barroso 492, 66090-000 Belém, PA, Brasil.

Tel: 91 211-4409, Fax 91 226-1284/226-5262

e-mail: pedrovasconcelos@iec.pa.gov.br

Recebido para publicação em 17/9/2002. 
entre si quanto à natureza dos transmissores e dos hospedeiros vertebrados e o local de ocorrência ${ }^{29}$. Eliminou-se a forma urbana na América em 1954, mas ainda hoje ela ocorre em África ${ }^{31376}$. A letalidade global varia de $5 \%$ a $10 \%$ mas entre os casos graves que evoluem com síndromes ictero-hemorrágica e hepatorenal pode chegar a $50 \%{ }^{57}$. Os pacientes mais acometidos são geralmente indivíduos jovens, do sexo masculino, realizando atividades agropecuárias e de extração de madeira, bem como ecoturistas que embrenham-se nas matas sem vacinação prévia ${ }^{57}$.
Clinicamente, a febre amarela pode se apresentar assintomática, oligossintomática, moderada, grave e maligna ${ }^{4857}$. Pode ser prevenida pelo uso da vacinação anti-amarílica mediante aplicação da vacina 17D, uma das vacinas de vírus vivo atenuado mais seguras e eficazes; recomenda-se a revacinação a cada 10 anos $^{45}$, embora estudos sorológicos em populações vacinadas uma única vez e vivendo fora da área de risco tenham demonstrado índices neutralizantes por várias décadas, o que sugere que uma única vacinação confere imunidade de longa duração, talvez por toda a vida ${ }^{1842}$.

\section{ETIOLOGIA}

O vírus da febre amarela pertence ao gênero Flavivirus da família Flaviviridae (do latim flavus = amarelo ${ }^{66}$. Ele pertence ao mesmo gênero e família de outros vírus responsáveis por doença no homem, entre os quais o Dengue, o West Nile, o Rocio e a encefalite de St. Louis. Embora apenas um sorotipo do vírus amarílico seja reconhecido, há pequenas alterações genéticas entre as cepas da América e da África que permitem atualmente caracterizar dois e cinco genotipos, respectivamente, não se sabendo se um é mais patogênico que o outro 3565 .

O vírus da febre amarela possui o genoma constituído de RNA de fita simples não segmentado, polaridade positiva, com cerca de 11 kilobases de comprimento. O genoma completo possui 10.862 nucleotídeos que codificam 3.411 aminoácidos ${ }^{43}$. Esse genoma possui uma única região codificante (ORF) com cerca de 10.233 nucleotídeos que vão codificar a formação das inúmeras proteínas virais e que é flanqueada por duas regiões não codificantes (NCR) de tamanho variável, sendo uma grande a 3'NCR com cerca de 511 nucleotídeos e uma pequena $5^{\prime} \mathrm{NCR}$ que possui 118 nucleotídeos. As regiões não codificantes, como indicativo, não codificam a formação de proteínas virais, mas são importantes para a regulação e expressão do vírus ${ }^{7650}$.

O vírion ou nucleocapsideo mede cerca de 25-40nm de diâmetro e é envolvido pelo envoltório bilaminar de natureza lipoproteica conhecido como envelope e que é originário da célula hospedeira. A partícula íntegra (vírion mais envelope) mede cerca de 40-50nm ${ }^{73}$. A região ORF do RNA viral expressa a síntese de três proteínas estruturais (prM, E e C) e sete não estruturais (NS1, NS2A, NS2B, NS3, NS4A, NS4B e NS5) cujas propriedades físico químicas e funções biológicas encontram-se resumidas na Tabela 1.

As proteínas estruturais codificam a formação da estrutura básica da partícula viral; a proteína prM codifica o precursor da proteína da membrana (M), já a proteína $\mathrm{E}$ dá origem ao envelope, enquanto a proteína C codifica a formação do capsídeo viral. São a essas proteínas que o organismo humano responde durante uma infecção com a produção dos anticorpos inibidores da hemaglutinação (IH) contra as glicoproteínas do envelope e neutralizantes $(\mathrm{N})$ contra a proteína $\mathrm{C}$ do capsídeo. Por outro lado, as proteínas não estruturais são responsáveis pelas atividades reguladoras e de expressão do vírus incluindo replicação, virulência e patogenicidade ${ }^{7}$.

Origem do vírus: até recentemente desconhecia-se a origem do vírus; não se sabia se ele já existia na América antes do comércio de escravos vindos da África. Pesquisas utilizando ferramentas moleculares indicam que as amostras de febre amarela da América perderam parte de uma seqüência repetitiva do genoma na região não codificante 3', o que não ocorre nas amostras africanas inclusive na vacina 17D e na amostra protótipo Asibi da qual derivou a amostra vacinal ${ }^{1356570}$. Isto praticamente encerra a polêmica, indicando que o vírus se originou na África.

\section{EPIDEMIOLOGIA}

A África responsabiliza-se por mais de $90 \%$ dos casos de febre amarela anualmente notificados à OMS. Isto corresponde a cerca de 5000 casos anuais. $\mathrm{Na}$ América do Sul estima-se a ocorrência de 300 casos anuais. Em alguns países da África há transmissão urbana da doença ${ }^{46}$.

Regiões afetadas: os riscos de adquirir a doença variam, sendo maior para os que se expõem sistematicamente e, praticamente, nulo aos que evitam as incursões em matas ou que vivem em áreas indenes da virose. É freqüente a pergunta: que pessoas ou grupos estão sob risco de adoecer por febre amarela?
E a resposta é simples: todas as pessoas não vacinadas e que se exponham às picadas dos transmissores em áreas de floresta, dentro da área endêmica da virose (especialmente onde esteja ocorrendo circulação do vírus) podem vir a se infectar (se o mosquito estiver infectado) e adoecer pela febre amarela. Ou seja, as áreas florestais e rurais da América do Sul e África (Figura 1), que correspondem às bacias dos rios Amazonas, Araguaia-Tocantins, Paraná e Orinoco na América do Sul, e Nilo e Congo na África ${ }^{57}$. Cumpre assinalar que casos da enfermidade têm sido reportados somente entre os paralelos $12^{\circ} \mathrm{N}$ e $12^{\circ} S^{56}$. 
Tabela 1 - Proteínas do vírus da febre amarela e suas possíveis funções*.

\begin{tabular}{|c|c|c|}
\hline Proteína & Descrição da proteína & Possíveis funções \\
\hline \multirow[t]{3}{*}{$\overline{\mathrm{C}}$} & Proteína do nucleocapsídeo viral & Formação do precursor do nucleocapsídeo, ligação do \\
\hline & & RNA, induz a formação de anticorpos \\
\hline & & protetores (neutralizantes) \\
\hline \multirow[t]{2}{*}{ prM } & Proteína transmembrana viral associada à célula & Morfogênese viral transporte? \\
\hline & de origem; precursor da proteína M & \\
\hline \multirow[t]{2}{*}{ M } & Proteína de membrana de partículas & Componente associado à ligação \\
\hline & virais maduras & e introdução do vírus na célula \\
\hline \multirow[t]{3}{*}{$E$} & Maior proteína do envelope. Muito conservada. & Montagem viral. Receptor de ligação \\
\hline & É o antígeno inibidor da hemaglutinação & Fusão com membrana celular. Maior antígeno \\
\hline & & viral (aglutinina). Induz formação de anticorpos IH \\
\hline \multirow[t]{2}{*}{ NS1 } & Associada à membrana. Forma dímeros & Maturação da partícula viral \\
\hline & Corresponde ao antígeno fixador do complemento & Participa na indução de anticorpos protetores \\
\hline NS2a & Hidrofóbica. Pouco conservada & Provavelmente associada à maturação de NS1 \\
\hline \multirow[t]{2}{*}{ NS2b } & Hidrofóbica. Pouco conservada & Possível componente da protease/replicase \\
\hline & & Forma componentes do capsideo durante a replicação viral \\
\hline \multirow[t]{2}{*}{ NS3 } & Altamente conservada & Multifuncional. Processa a poliproteína \\
\hline & & Participa da replicação do RNA. Possível helicase \\
\hline \multirow[t]{2}{*}{ NS4a } & Hidrofóbica. Pouco conservada & Possível componente da replicase \\
\hline & & Associada à membrana \\
\hline NS4b & Hidrofóbica. Pouco conservada & Possível componente da replicase \\
\hline \multirow[t]{2}{*}{ NS5 } & Altamente conservada & Polimerase viral. Associada ao \\
\hline & & RNA viral. Participa da replicação viral \\
\hline
\end{tabular}

*adaptado de Chambers et al, $1990^{7}$.

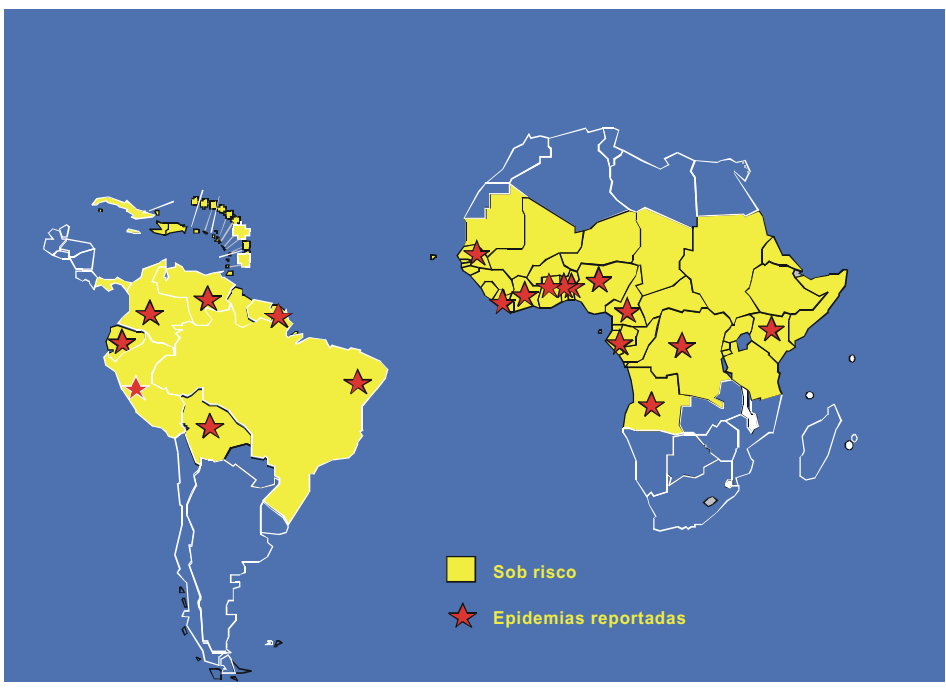

Figura 1 - Áreas sob risco de febre amarela e países que reportaram epidemias no período de 1985 a 2000. Fonte: OMS. 
Suscetibilidade e grupos afetados: a suscetibilidade é geral e irrestrita, desconhecendo-se maior ou menor resistência ao vírus da febre amarela no tocante a raça, cor ou faixa etária 5 . Na América do Sul e em particular no Brasil, a doença tem sido documentada principalmente entre lenhadores, seringueiros, vaqueiros, garimpeiros, caçadores, indígenas, ribeirinhos dos rios, nos focos enzoóticos amazônicos e na África, e em turistas (turismo ecológico). Mais de $80 \%$ dos casos ocorrem em indivíduos do sexo masculino com idade variando entre 14 a 35 anos. Essa preferência se deve à maior exposição e não a maior susceptibilidade ao vírus ${ }^{57}$. Nos últimos 5 anos, observou-se tendência de aumento de casos no sexo feminino e entre menores de 15 anos, especialmente nos pacientes oriundos da Amazônia ${ }^{58} 64$ (Vasconcelos PFC, dados não publicados).
Mortalidade e letalidade: a mortalidade global da febre amarela situa-se entre $5-10 \%$, percentual elevado quando comparado a outras viroses inclusive o dengue $^{51}$. Mas a letalidade dos casos graves revelouse maior e no Brasil oscila entre 40\%-60\%58 5962 . Nos últimos 31 anos do século XX, cobrindo o período de 1970-2000 e mais o ano de 2001 foram notificados 4.543 casos de febre amarela na América do Sul (Figura 2), todos da forma silvestre. O Peru, com 2.341 casos ( $51,5 \%)$ e a Bolívia com 912 casos $(20,1 \%)$ são os dois países que mais reportaram casos. O Brasil ocupa o terceiro lugar com 849 casos $(18,7 \%)$ notificados no período ${ }^{39}$. A situação do Brasil preocupa. Na última década o número anual de casos notificados raramente excedeu 60 notificações mas a letalidade mostrou-se elevada e a tendência tem sido de aumento do número de ocorrências (Figura 3$)^{63}$.

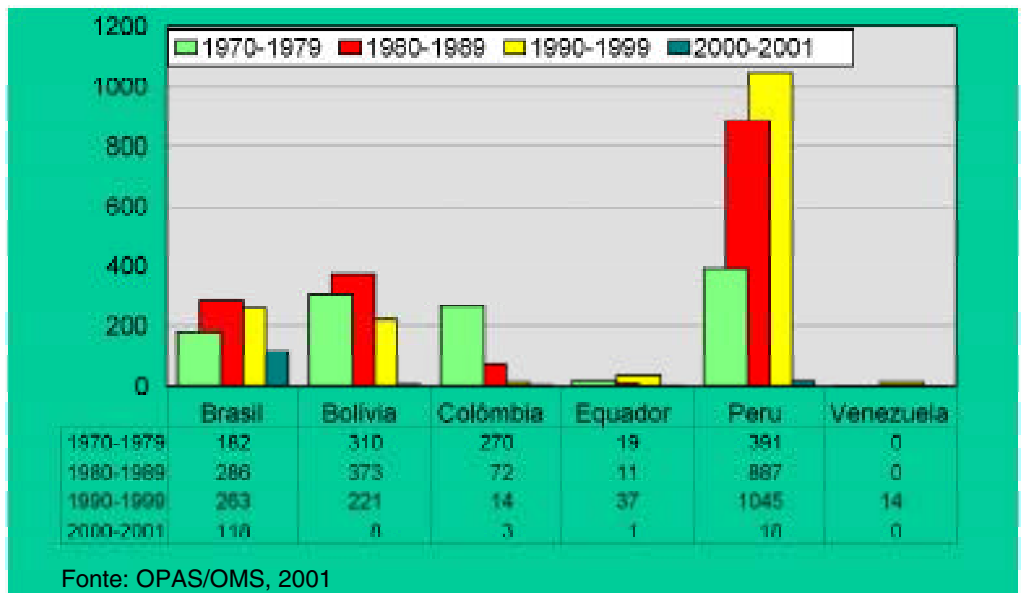

Figura 2 - Casos de febre amarela notificados à Organização PanAmericana de Saúde (OPAS) por país na América do Sul, 1970-2001 (até maio).

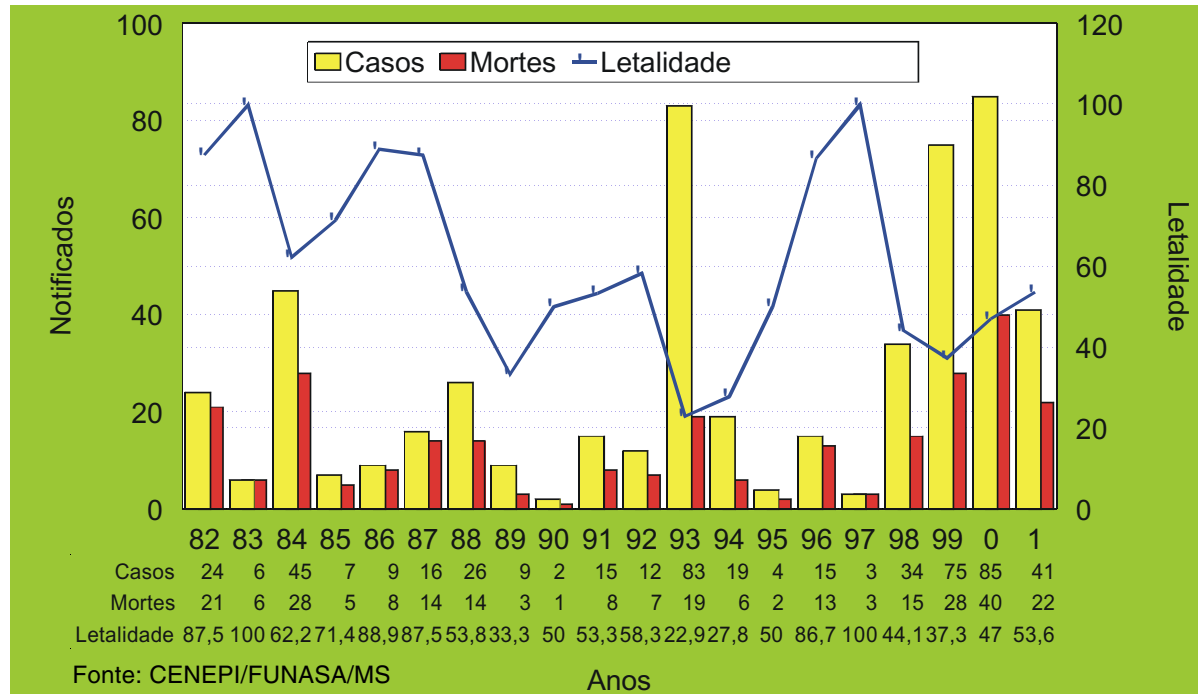

Figura 3 - Casos, mortes e letalidade por febre amarela no Brasil, 1982-2001. 
Áreas de risco e cobertura vacinal: no Brasil, admitem-se três áreas epidemiológicas de risco da febre amarela (Figura 4) a saber: área endêmica, área de transição (também conhecida como epizoótica ou de emergência) e área indene ${ }^{9}{ }^{58}{ }^{63}$. Atualmente, a área endêmica inclui as regiões Norte e Centro Oeste e o Estado do Maranhão. Esta área corresponde a mais de 2/3 do território nacional onde vive uma população de cerca de 30 milhões de habitantes ${ }^{16}$. Nos últimos anos, face ao significativo aumento na ocorrência e circulação do vírus amarílico, a área epizoótica aumentou, passando a incluir além da parte ocidental de Minas Gerais, São Paulo e Paraná, classicamente consideradas áreas de risco, as partes ocidentais dos estados do Piauí e Bahia no Nordeste, e Santa Catarina e Rio Grande do Sul na região Sul ${ }^{9}$. Este aumento da área de transição deveu-se ao reconhecimento pelo
Ministério da Saúde da necessidade de estender a faixa de proteção às áreas com circulação epizoótica recente inclusive em áreas com coberturas florestais rarefeitas, os capões de mato e, também, devido a grande mobilidade observada na população. A área de transição corresponde a uma população de cerca de 18 milhões de habitantes. Já a área indene corresponde às áreas da costa brasileira indo desde o Piauí até o Rio Grande do Sul, onde vivem cerca de 118 milhões de habitantes ${ }^{16}$.

A imunidade das populações vivendo nessas áreas varia consideravelmente. $\mathrm{Na}$ área endêmica estima-se que cerca de $95 \%$ da população já esteja vacinada contra a febre amarela. Observa-se índice similar ou ligeiramente inferior na área de transição. Já na área indene, a cobertura vacinal, ressalvadas raras exceções, é muito baixa ou praticamente nula ${ }^{16}$.
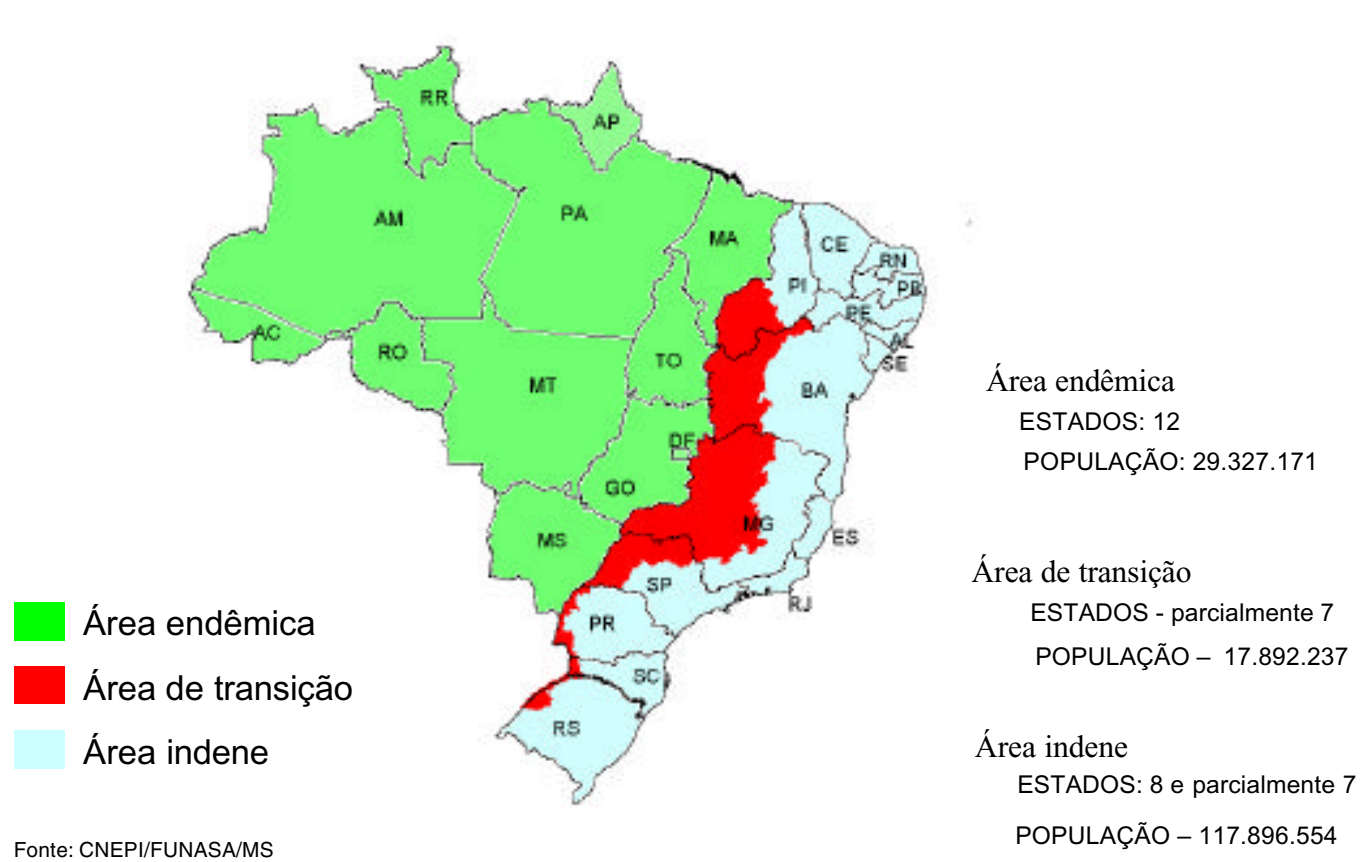

Figura 4 - Áreas epidemiológicas de febre amarela no Brasil, 2001.

Ciclos de transmissão. O vírus da febre amarela mantém-se em dois ciclos básicos: um ciclo urbano simples do tipo homem-mosquito onde o Aedes aegypti responsabiliza-se pela disseminação da doença e outro silvestre complexo, onde várias espécies de mosquitos responsáveis pela transmissão diferem: na África, os mosquitos Aedes e na América os mosquitos Haemagogus e Sabethes ${ }^{50}$.

Ciclo urbano: neste ciclo, a transmissão pelo Aedes aegypti é feita diretamente ao homem sem necessitar da presença de hospedeiros amplificadores, ou melhor, o próprio homem infectado e em fase virêmica atua como amplificador e disseminador do vírus na população. Em geral, também é o homem que introduz o vírus numa área urbana. Uma vez introduzido o vírus no ambiente urbano, o paciente infectado desenvolverá viremia, pode expressar a doença e servir de fonte de infecção a novos mosquitos (Aedes aegypti). Assim, o ciclo se perpetua, até que se esgotem os suscetíveis ou se realize vacinação em massa da população para bloquear a transmissão ${ }^{57}$.

Cumpre ressaltar que a última grande epidemia urbana em território brasileiro ocorreu em 1929 na 
cidade do Rio de Janeiro. Já os últimos casos urbanos reconhecidos foram reportados no município de Sena Madureira, no Estado do Acre e ocorreram em $1942^{15}$. Nas Américas, os últimos casos ocorreram somente 12 anos mais tarde, em Trinidad, em 195429. Desde então, nenhum caso urbano foi diagnosticado ou oficialmente notificado nas Américas, a despeito da intensa reinfestação do Aedes aegypti ocorrida na América do Sul, acompanhada de extensas epidemias de dengue 30465963 , salvo pelo registro não oficial de seis casos em Santa Cruz de la Sierra, na Bolívia55.

Ciclos silvestres: o ciclo silvestre foi reconhecido na década de $1930^{49} 51$. Além de complexo persiste imperfeitamente compreendido e varia de acordo com a região onde ocorre.

Em África, várias espécies de mosquitos do gênero Aedes são responsáveis pela transmissão, principalmente Aedes africanus, Aedes furcifer e Aedes simpsonili 67 enquanto nas Américas os mais importantes transmissores são Haemagogus janthinomys, Haemagogus albomaculatus, Haemagogus leucocelaenus, e Sabethes chloropterus ${ }^{10} 115067$. Os mosquitos além de serem transmissores são os reservatórios do vírus pois uma vez infectados assim permanecem por toda vida, ao contrário dos macacos que, como os homens, ao se infectarem morrem ou curam-se, ficando imunes para sempre. Portanto, os macacos atuam tão somente como hospedeiros amplificadores da virose ${ }^{57}$.

Em África há diferentes níveis de transmissão: silvestre, rural ou peri-urbana e urbana ${ }^{13}$. A transmissão silvestre em áreas florestais e de savanas úmidas se faz principalmente pelo Aedes africanus, mosquito de

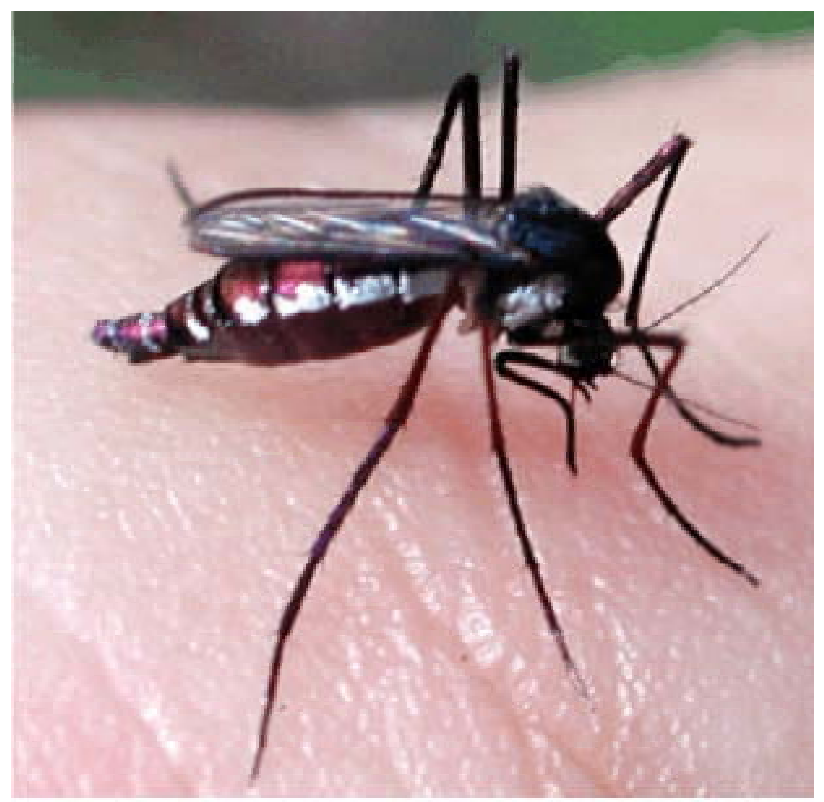

Figura 5 - Mosquito Haemagogus janthinomys principal transmissor da febre amarela na América do Sul (foto gentilmente cedida por Dr. Nicolas Dégallier, ( ${ }^{\circledR}$ IRD, 2001). hábitos estritamente silvestres. Em áreas de savanas, em geral da África Ocidental, os transmissores são principalmente o Aedes furcifer e o Aedes taylori. Nas savanas secas o Aedes luteocephalus é o transmissor, ocorrendo em vilas localizadas próximo de florestas, em particular na Nigéria. Na África Oriental e Central, além do Aedes africanus, o Aedes pseudoafricanus tem sido o vetor mais associado aos surtos de febre amarela silvestre ${ }^{1367}$.

$\mathrm{Na}$ África Oriental há um vetor de ligação entre os ciclos urbano e silvestre, representado pela espécie Aedes simpsoni, que sai da mata indo picar os indivíduos nas periferias das cidades, podendo, além disso, manter a transmissão urbana contínua, ainda que limitada a essas áreas ${ }^{67}$.

Nas Américas não se encontram os transmissores africanos. No entanto, outros mosquitos mostram-se responsáveis pela transmissão da forma silvestre da arbovirose. No Novo Mundo, os mosquitos dos gêneros Haemagogus (Haemagogus janthinomys, Haemagogus albomaculatus, Haemagogus leucocelaenus, etc.) e Sabethes (Sabethes chloropterus, Sabethes soperi, Sabethes cyaneus, etc.) constituem os vetores da febre amarela ${ }^{1161}$.

Cerca de $98 \%$ de todos os isolamentos do vírus da febre amarela procedentes de mosquitos, obtidos no Instituto Evandro Chagas, originaram-se desses gêneros e só excepcionalmente as espécies de outros gêneros foram encontradas infectadas. É o caso do Aedes fulvus, Aedes scapularis e Psorophora albipes cada um com um único isolamento (Vasconcelos PFC: dados não publicados).

O principal transmissor, no entanto, é o mosquito Haemagogus janthinomys (Figura 5$)^{40}$. Este mosquito apresenta a maior distribuição geográfica conhecida entre as espécies desse gênero. Ele possui hábitos estritamente silvestres e pica o indivíduo que se expõe na mata (floresta), ou seja, quando penetra em seu nicho ecológico ${ }^{11}$. Esta espécie apresenta as melhores condições para transmitir o vírus amarílico pois mostrase extremamente suscetível ao mesmo. Em infecções experimentais, se infecta com baixas doses infectantes. É primatófila, ou seja, se alimenta preferencialmente em macacos e, secundariamente, no homem, e apresenta atividade diurna, período em que a maioria dos que adoecem da enfermidade realizam suas atividades ou incursões nas matas. Durante as epidemias os mosquitos dessa espécie que habitam a copa das árvores, também têm sido encontrados freqüentemente infectados com elevados índices de infecção ${ }^{11} 345864$. Estas características explicam a facilidade em transmitir a virose, e credencia este mosquito, por conseguinte, como o principal transmissor da febre amarela no Brasil e em quase todos os países da América do Sul onde a arbovirose revela-se endêmica. Ademais, recentemente, Mondet et al ${ }^{34}$ reportaram a ocorrência de transmissão transovariana 
em natureza nessa espécie, fato anteriormente apenas obtido em condições experimentais com Haemagogus equinus ${ }^{14}$.

Outras espécies de Haemagogus, como Haemagogus albomaculatus (Região do Baixo Amazonas, Pará), Haemagogus leucocelaenus (Região Sul), bem como, de Sabethes como Sabethes chloropterus (Mato Grosso do Sul e Maranhão), Sabethes cyaneus, Sabethes glaucodaemone Sabethes soperi (Minas Gerais) têm sido ocasionalmente encontrados infectados, o que pode significar que esses mosquitos apresentam papel secundário na manutenção do vírus da febre amarela em natureza $^{101161 .}$.

Hospedeiros vertebrados: tanto em África quanto na América, os hospedeiros silvestres primários do vírus da febre amarela são primatas não humanos. No continente africano, os macacos mostram-se mais resistentes ao vírus e, por conseguinte, ainda que desenvolvam a infecção, raramente sucumbem à mesma. Isto permite a rápida renovação da população símia, o que facilita a manutenção do vírus numa área e encurta os períodos interepidêmicos ${ }^{50}$. No Novo Mundo, todos os gêneros de primatas não humanos reconhecidos e infectados experimentalmente, se mostraram sensíveis e suscetíveis ao vírus amarílico ${ }^{50}$. Ademais, corroborando esses achados, revela-se comum a presença de anticorpos contra a febre amarela em símios capturados.

Nas Américas, alguns macacos mostram grande susceptibilidade ao vírus amarílico como, por exemplo, o guariba (gênero Alouatta); outros apresentam grande resistência, como o macaco prego (gênero Cebus) ${ }^{50}$. Os guaribas ou bugios, infectados com doses mínimas do vírus da febre amarela desenvolvem infecção fulminante, comportamento similar aos casos humanos fatais. O máximo que se consegue é retardar o desfecho fatal quando se usa dose infectante menor que o encontrado em mosquitos naturalmente infectados e que se acredita ser a dose que infecta os símios. Os macacos pregos se mostram mais refratários ao vírus da febre amarela ${ }^{51}$. Esses animais mesmo infectados com doses maciças raramente desenvolvem doença grave. Eles desenvolvem infecção subclínica ou quadro febril fugaz, há viremia, e segue-se a produção de anticorpos protetores que neutralizam futuras reinfecções ${ }^{57}$.

Suspeita-se que outros animais, como os marsupiais arboreais e preguiças, possam ter papel secundário no ciclo de manutenção viral, especialmente em áreas onde os macacos estejam ausentes ou já imunes ao vírus. Na Colômbia, por exemplo, na década de 1940, ocorreu epidemia de febre amarela na ausência de macacos e apenas os marsupiais foram encontrados com anticorpos anti-amarílicos ${ }^{29}$.

Impacto das epidemias: no passado a ocorrência de epidemias de febre amarela urbana provocava impacto devastador na economia de um país. Prejudicava-se o turismo, as exportações eram reduzidas drasticamente e impunha-se quarentena aos navios oriundos dos mesmos ${ }^{50}$. O caos abalava a economia do país, interrompendo as atividades produtivas de geração de renda e riqueza da nação ${ }^{4}$.

Ainda hoje, as epidemias mesmo sendo limitadas a pequenos surtos de febre amarela silvestre apresentam repercussão. Mesmo dispondo-se de vacina eficaz que rapidamente pode bloquear ou interromper a transmissão, o medo leva a corrida aos postos de vacinação. A febre amarela, ao lado do cólera e da peste são as três doenças sujeitas ao Regulamento Sanitário Internacional. A notificação internacional é compulsória para que as medidas preventivas sejam adotadas pelos países vizinhos e para proteger os turistas estrangeiros e alertá-los sobre a necessidade de se vacinarem ${ }^{45}$.

\section{PATOGENIA}

Os aspectos patogênicos da infecção pelo vírus da febre amarela são conhecidos em parte e as informações acumuladas derivam de estudos em primatas não humanos, hamsters, camundongos e achados histopatológicos em casos humanos fatais ${ }^{2} 5269$.

A inoculação do vírus amarílico em camundongos desencadeia encefalite fatal. Por outro lado, a infecção experimental de macacos determina tropismo semelhante ao observado no homem, isto é, viscerotropismo tendo como órgão alvo o fígado. Este tipo de apresentação clínica nos símios os transformou no modelo ideal para estudos experimentais face à semelhança com o quadro desenvolvido pelos seres humanos. Entretanto, os problemas éticos e os custos elevados desses animais inviabilizam os estudos em primatas $^{2325153}$.

Os hamsters (Mesocricetus auratus) têm sido usados como modelo alternativo para o estudo do viscerotropismo do vírus da febre amarela; há vantagens econômicas aliados ao fácil manejo dos animais em laboratório ${ }^{52}{ }^{69}$. Em infecções experimentais, usando hamsters jovens, encontra-se o vírus na corrente sangüínea cerca de 48 horas após a inoculação. O título viral cresce rápidamente até 96 horas. Decresce em seguida também rapidamente, para raramente ser encontrado após 120 horas da inoculação ${ }^{52}$. Nesses animais as lesões iniciais caracterizam-se por aumento do núcleo e marginação da cromatina. Caracteristicamente, as lesões se localizam nos lóbulos hepáticos e atingem dentro de um mesmo lóbulo, certas estruturas, preservando outras. Assim é que num lóbulo, as áreas centrais entre o espaço porta e a veia centro lobular são mais atingidas pela necrose, conhecida como necrose médio-zonal, semelhante ao que ocorre em humanos e símios ${ }^{69}$.

No fígado de macacos rhesus experimentalmente inoculados, o vírus infecta as células de Küpffer e os hepatócitos. Nas primeiras, determina degeneração acidófila em zonas focais durante o período inicial de 
replicação, cerca de 24 h após a inoculação ${ }^{53}$. Em seguida, ocorre degeneração baloniforme e posteriormente, necrose do tipo hialina detectável cerca de 3 dias pós a inoculação, sem ocorrer aparentes lesões nos hepatócitos ${ }^{53}$. Nessas células, o vírus amarílico causa necrose em grandes extensões do parênquima hepático, preferencialmente nas áreas médio-zonais, poupando as extremidades do lóbulo, sendo raro o encontro de células necrosadas antes do terceiro dia pós-inoculação 24053

A lesão no hepatócito é principalmente necrose de coagulação hialina, com pouco processo inflamatório. Algumas vezes, virtualmente não se encontram células inflamatórias, especialmente nas áreas onde a apoptose mostra-se mais evidente ${ }^{31}$. Noutro experimento em símios, Monath et $\mathrm{al}^{32}$ relatam o encontro do vírus no fígado cerca de $24 \mathrm{~h}$ após a inoculação. Em seguida, o vírus foi encontrado nos rins, baço, medula, linfonodos e coração. O quadro hepático típico, com corpúsculos de Councilman-Rocha Lima e necrose médio-zonal constitui evento tardio, tornando-se evidente nas 24 a $48 \mathrm{~h}$ que antecedem o óbito. Se desconhece a razão do tropismo viral pelas células da região médio-zonal. A ocorrência de apoptose também constitui evento tardio da infecção e tal agressão explica a virtual ausência de processo inflamatório celular na febre amarela, a preservação da arquitetura celular na maioria dos casos e a completa regeneração do órgão sem fibrose nos sobreviventes ${ }^{32}$. O mesmo padrão tem sido observado em hamsters inoculados via intraperitonal com amostra viral adaptada a esses animais ${ }^{69}$.

No homem, após a introdução do vírus amarílico na circulação pela picada do transmissor, o vírus em poucas horas atinge os linfonodos regionais e desaparece da circulação nas 24 horas seguintes. Nos linfonodos, o vírus amarílico infecta preferencialmente células linfóides e macrófagos, aí realizando o ciclo replicativo. Posteriormente, com a liberação das partículas virais pelas células, elas são levadas pelos vasos linfáticos até a corrente sangüínea, iniciando o período de viremia, e daí pela via hemática atingem o fígado. O período de viremia varia de acordo com a apresentação clínica, sendo de algumas horas até dois dias nas formas frustras e leves, respectivamente, e de até cinco a sete dias nas formas mais graves. Este período de viremia coincide com o início do período prodrômico da enfermidade e em particular com a febre e constitui a fase em que o sangue humano torna-se infectante para os vetores não infectados ${ }^{3157}$

Nos seres humanos, os achados histopatológicos assemelham-se aos observados em macacos e decorrem principalmente de exames de necropsia.

Ainda que a necrose médio-zonal seja observada em outras viroses como o dengue e mesmo em alguns casos de hepatite fulminante, ela predomina na infecção amarílica. Nas áreas médio-zonais necrosadas na febre amarela, raramente há desorganização da arquitetura normal. Na hepatite fulminante, a desorganização da arquitetura hepática com destruição das traves de Remack torna-se evidente. Por vezes, entretanto, quando a necrose na febre amarela mostra-se muito extensa o diagnóstico histopatológico fica muito difícil ${ }^{41}$.

Dentro da área necrosada observam-se discreto infiltrado inflamatório com predomínio de células mononucleares, restos celulares, e vários tipos e graus de lesões degenerativas. A mais característica e tida como indicativa de febre amarela, ainda que não patognomônica, pois, tem sido descrita também na malária por Plasmodium falciparum, nas hepatites virais, no dengue, na mononucleose infecciosa e em outras febres hemorrágicas virais, é a degeneração hialina, acidófila dos hepatócitos, conhecida como corpúsculo de Councilman-Rocha Lima. Mostra-se também comum a degeneração gordurosa (esteatose), observada em células necrosadas e preservadas. Mais raramente, encontram-se os corpúsculos de Torres e Villela, estes encontrados nos hepatócitos, células de Küpffer e macrófagos ${ }^{4157}$.

\section{QUADRO CLÍNICO}

A resposta à infecção amarílica revela-se ampla e variável. A febre amarela pode ser definida como uma doença infecciosa viral aguda de curta duração cuja gravidade varia, podendo ocorrer sob formas oligossintomáticas, até formas fulminantes, em que os sintomas clássicos de icterícia, albuminúria e hemorragias estão presentes. Mas também causa infecçoes assintomáticas ou sub-clínicas que, junto com as formas leves da doença, somente são surpreendidas pelos exames laboratoriais específicos ${ }^{23} 3157$. O período de incubação médio é de 3 a 6 dias mas pode ser de até 10 dias.

Portanto, o conceito de que a febre amarela constitui doença invariavelmente fatal não se justifica. Estima-se que pelo menos $90 \%$ dos casos de febre amarela com expressão clínica sejam das formas classificadas como leve e oligossintomática, raramente diagnosticadas e que somente $10 \%$ sejam das formas graves associadas com elevada letalidade ${ }^{57}$. Por isso, a enorme subnotificação caracteriza o iceberg da febre amarela (Figura 6).

Cumpre ressaltar que algumas pessoas desenvolvem quadros assintomáticos, subclínicos e formas leves da doença, de difícil diagnóstico clínico, exceto na vigência de epidemia.

Essas formas frustas freqüentemente ocorrem em crianças de baixa idade, cujas mães foram vacinadas $e$ que transmitiram (via transplacentária durante a gestação) anticorpos maternos do tipo IgG. Os índios, ao adquirirem imunidade materna e ao longo de sua vida, constituem outro grupo em que a doença apresenta formas leves ou assintomática da 


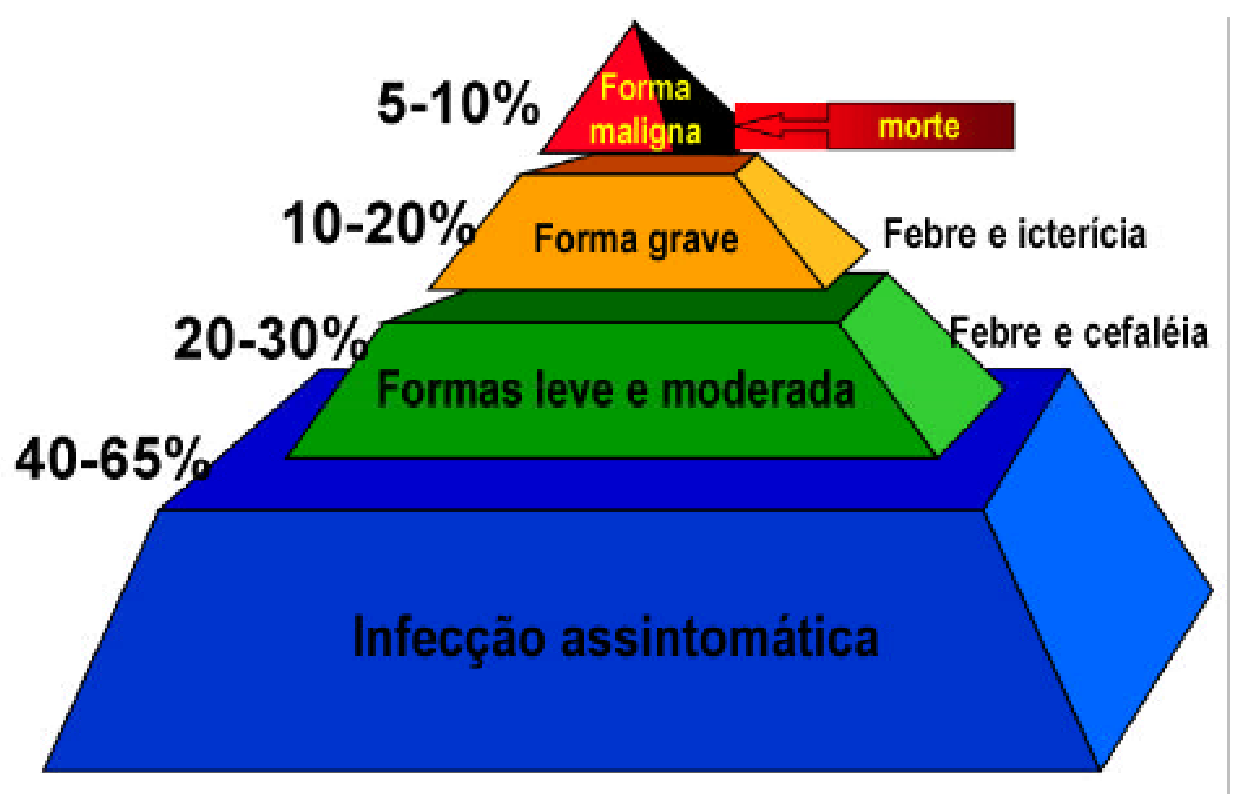

Figura 6 - O “iceberg” da febre amarela. Distribuição das formas clínicas.

enfermidade. Por vezes, numa mesma família, alguns adoecem de formas brandas, enquanto outros sucumbem com as formas graves da doença ${ }^{23} 57$.

Os demais indivíduos desenvolvem formas clínicas mais exuberantes e outros exibem quadro graves. Aí se incluem as pessoas não vacinadas e, portanto, completamente indefesas à enfermidade. Tais pessoas quando acometidas pela arbovirose, desenvolvem os quadros clássicos de febre amarela, graves e com elevado percentual de fatalidade (Tabela 2).

Tabela 2 - Apresentações clínicas da febre amarela no homem ${ }^{57}$.

\begin{tabular}{llll}
\hline Forma clínica & Evolução (dias) & Principais manifestações & Grupos mais acometidos \\
\hline Leve & até 2 & febre e cefaléia & $\begin{array}{l}\text { crianças com anticorpos maternos (IgG) } \\
\text { adquiridos } \\
\text { podessoas com imunidade para } \\
\text { outros Flavivirus }\end{array}$ \\
& $2-3$ & $\begin{array}{l}\text { sintomas anteriores e mais } \\
\text { mialgias, artralgias, náuseas, } \\
\text { vômitos e astenia }\end{array}$ & $\begin{array}{l}\text { agricultor, pescador, caçador, lenhador, } \\
\text { turista e outros suscetíveis com }\end{array}$ \\
Grave & $3-5$ & $\begin{array}{l}\text { além dos anteriores, icterícia, } \\
\text { hematêmese ou oligúria }\end{array}$ & imunidade cruzada para Flavivirus \\
& & Mesmo grupo de pessoas sem imunidade \\
Maligna & $\geq 6$ & todos os sintomas clássicos & cruzada para outros Flavivirus
\end{tabular}

* A resposta sorológica para um dado vírus desse gênero, apresenta no indivíduo infectado certa imunidade cruzada, que é parcial e se supõe conferir algum grau de proteção contra infecções provocadas por outros Flavivirus.

Formas leve e moderada: a sintomatologia observada nas formas leve e moderada revela-se incaracterística e confunde-se com a encontrada em outras doenças infecciosas comuns em áreas endêmicas entre as quais as mais importantes são a malária, as hepatites virais, a febre tifóide e a mononucleose infecciosa.

Em geral, os sintomas na forma leve restringem-se à febrícula ou febre moderada de início súbito que pode ou não vir acompanhada de cefaléia discreta, astenia ou indisposição passageira e tontura. Esse quadro evolui por algumas horas até dois dias, findos os quais o paciente se recupera inteiramente sem seqüelas. Apresenta-se de forma silenciosa de difícil diagnóstico mesmo durante as epidemias de febre amarela, podendo ser confundida com mal estar passageiro, resfriado e enxaqueca. Apenas as provas específicas definem o diagnóstico.

$\mathrm{Na}$ forma moderada, o quadro clínico mostra-se arrastado e conspícuo. O paciente refere início súbito com febre e cefaléia. Além desses sintomas ele pode apresentar náuseas com ou sem vômitos, mialgias e artralgias que não incomodam o paciente nem dificultam 
a sua locomoção. A cefaléia costuma ser duradoura e intensa. A febre se eleva mais e só cede após o uso de antitérmicos; a astenia mostra-se mais pronunciada. Nesta forma, pelo menos um dos sintomas clássicos da doença costuma acompanhar o curso clínico. De fato, epistaxe, ligeira albuminúria, e subicterícia acontecem. Às vezes, observa-se o sinal de Faget, isto é, a ocorrência de bradicardia acompanhando a febre elevada. O período de estado, revela-se mais longo, durando em média de dois a três dias e a recuperação mostra-se completa e sem seqüelas. Diagnosticam-se essas formas no curso de epidemias em locais onde ocorreram ou estão ocorrendo outros $\operatorname{casos}^{23}$.

Formas grave e maligna: na forma grave o quadro clínico inicia-se abruptamente com febre elevada e cefaléia intensa. Nesta forma o sinal de Faget torna-se evidente. A cefaléia se intensifica. As dores musculares generalizam-se. As náuseas e os vômitos incomodam. Há icterícia franca, albuminúria persistente e por vezes acompanhada de oligúria. Descrevem-se hemorragias, especialmente hematêmese e sangramento uterino. Esta forma cursa por até 7 dias, usualmente por 5 dias. A febre em geral mostrase persistente. Infecção abortiva desta forma pode ser grave mas costuma ser mais curta com evolução de 3-4 dias ${ }^{23}$.

A forma grave ou moderadamente grave é clinicamente diagnosticada porque pelo menos um dos sintomas clássicos da enfermidade como, hematêmese, icterícia ou oligúria/anúria, podem ser observados. $\mathrm{Na}$ forma maligna todos os sintomas clássicos encontramse presentes.

$\mathrm{Na}$ forma maligna da febre amarela os pacientes sempre apresentam os três sintomas clássicos que caracterizam a falência hepato-renal. Algumas vezes o quadro hepático se superpõe ao quadro renal e a icterícia mostra-se exuberante com bilirrubina e aminotransferases muito elevadas, mas com aumento não muito pronunciado de uréia e creatinina que sugere não haver comprometimento renal acentuado. Outras vezes observase o inverso. Entretanto, o mais comum é o quadro exuberante, completo, com riqueza de manifestações clínicas e importante envolvimento hepato-renal. O quadro evolui em duas fases ou períodos com um período de remissão entre as mesmas. Ressalte-se, no entanto, que nem sempre é possível se separar tais fases ${ }^{23}$.

A sintomatologia da forma clássica (maligna) da febre amarela caracteriza-se pelo início abrupto. Inicialmente surge febre elevada, informando o paciente ter-se sentido bem e executado seus afazeres algumas horas antes ${ }^{57}$. À febre não se acompanha de elevação da pulsação. A temperatura pode atingir $39^{\circ}$ ou $40^{\circ} \mathrm{C}$. Pouco tempo depois do aparecimento da febre surge cefaléia holocraniana de tal intensidade que o paciente, muitas vezes, reclama a prescrição de analgésicos potentes. Acompanhando esse quadro, as dores musculares generalizadas, especialmente nas costas intensificam-se. As náuseas e os vômitos tornam-se um tormento. Esse quadro que evolui por 2 a 3 dias e corresponde ao período prodrômico, fase infecciosa ou de viremia da enfermidade, completa-se pela presença de astenia, anorexia, prostração e tontura ${ }^{23} 57$.

Em muitos pacientes, seguindo-se ao período infeccioso, há o período que se caracteriza por sensação de melhora e cura iminente, em que se observa diminuição da febre. As dores musculares diminuem e a cefaléia torna-se suportável. O período de remissão costuma durar, de algumas horas até 1-2 dias, em geral um dia. Em seguida, ao contrário dos indivíduos que desenvolvem as formas leve, moderada e grave que realmente curam-se, esses pacientes repentinamente apresentam piora do quadro.

Inicia-se então o período de intoxicação, toxêmico ou fase de localização, em que o vírus deixa de circular no sangue sendo encontrado principalmente no fígado e baço, mas também no coração, linfonodos e outros órgãos. As náuseas se intensificam e os vômitos agravam-se ou, se anteriormente ausentes, surgem repentinamente. Estes, de início, costumam ser alimentares, mas com a evolução tornam-se hemorrágicos. Outras manifestações hemorrágicas são também usualmente encontradas como, por exemplo, as hemorragias do tegumento, das gengivas e do ouvido (Figura 7). No trato gastrointestinal, observase melena ${ }^{57}$.

Acompanhando ou mesmo antecedendo as hemorragias, há plaquetopenia, muitas vezes tão acentuada que pode chegar a menos de $20.000 / \mathrm{cm}^{3}$ de sangue. Alguns pacientes, mesmo apresentando níveis tão baixos de plaquetas, não sangram e outros com taxas entre 50.000 a 100.000 plaquetas apresentam hemorragias exuberantes, por vezes incoercíveis e responsáveis pelo óbito. Parece que nem sempre a gravidade da hemorragia associa-se ao número de plaquetas, mas aos problemas ligados à ativação do complemento e ao consumo dos fatores de coagulação, indicando que na febre amarela há coagulação intravascular disseminada ${ }^{47}$.

Estudos realizados durante a epidemia de Goiás, em 1973, demonstraram que em casos graves hospitalizados, identificaram-se diversas alterações na crase sangüínea. Os mais alterados foram os fatores II, V, VII, VIII, IX e X, bem como os tempos de sangria, de coagulação e da protrombina, com redução de fibrinogênio e presença dos produtos degradados da fibrina que, em conjunto, sugerem que o sangramento decorre de múltiplas causas, e que predominam a plaquetopenia e a redução da síntese dos fatores da coagulação ${ }^{47}$. Ou seja, a febre amarela evolui com coagulopatia de consumo e coagulação intravascular disseminada ${ }^{3157}$.

Acompanhando esse quadro surge icterícia (dessa cor amarela da pele e das escleróticas dos olhos e da febre, resulta o nome da doença). A icterícia é basicamente do tipo verdínica e se deve, sobretudo, ao aumento da fração direta. Encontram-se valores de bilirrubina acima de $10 \mathrm{mg} \%$ e mesmo $20-30 \mathrm{mg} \%$. As aminotransferases elevam-se muito, com valores que 


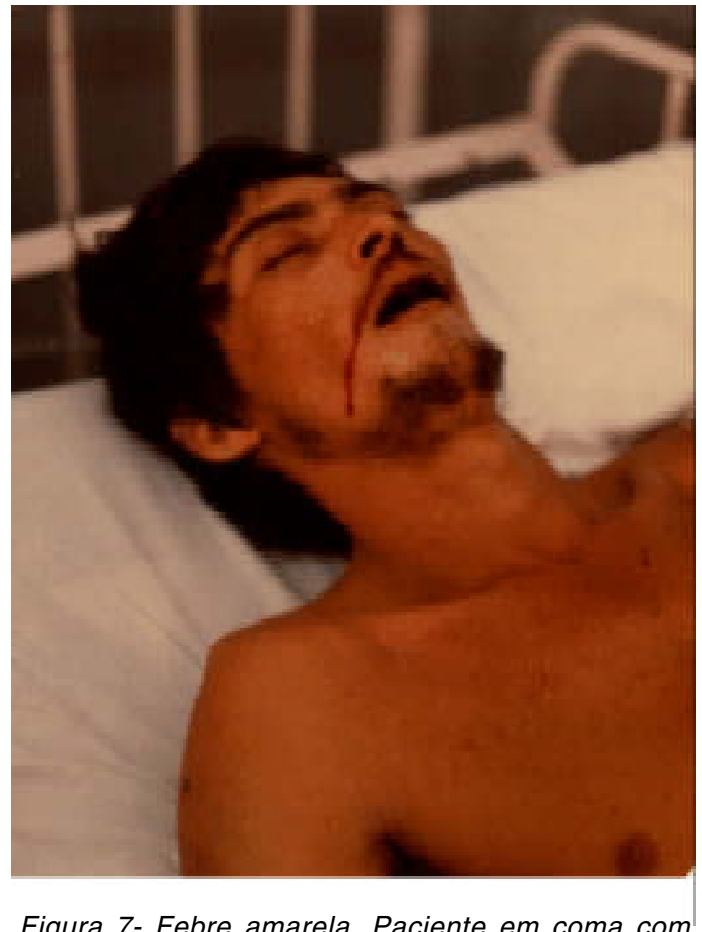

Figura 7- Febre amarela. Paciente
quadro maligno. Notar hemorragia.

podem chegar a $5.000 \mathrm{U} / \mathrm{cm} 3$ de sangue ${ }^{57}$. Note que a concentração de AST (aspartato aminotransferase) freqüentemente ultrapassa a da ALT (alanino aminotransferase), presumivelmente devido ao efeito citopático do vírus no miocárdio e músculos esqueléticos ${ }^{31}$.

Estudos realizados em África mostraram que as taxas de aminotransferases séricas indicam a gravidade da doença e predizem a evolução clínica dos pacientes com febre amarela. Os autores mostraram que os valores médios de AST e ALT de $2.766 \mathrm{U}$ e $660 \mathrm{U}$, respectivamente, foram observados em casos fatais, enquanto que nos casos não fatais os valores dessas enzimas foram de $929 \mathrm{U}$ e $351 \mathrm{U}$, respectivamente ${ }^{38}$.

Por volta do $5^{\circ}$ até o $7^{\circ}$ dias do período de estado, instala-se a insuficiência renal que se manifesta inicialmente pela diminuição do volume urinário. Observa-se com freqüência os pacientes que não urinam $500 \mathrm{ml}$ durante $24 \mathrm{~h}$ mesmo mantendo-se a boa hidratação. Nesta fase se não for vigorosamente tratada, a oligúria rapidamente evolui a anúria devido à necrose tubular aguda generalizada que se instala. Os óbitos ocorrem com mais freqüência nesse período ${ }^{21}$.

Em África, tem sido freqüente a ocorrência de formas fulminantes com evolução fatal em até três dias ${ }^{48}$. Nestes casos, predomina a insuficiência renal e quase não há icterícia ou alterações hepáticas. Por outro lado, mais raramente, ocorrem mortes tardias. Tais casos devemse a lesões cardíacas tardias.
Nos casos em que a icterícia revela-se intensa e os níveis séricos de bilirrubina elevam-se muito, a encefalopatia constitui sinal de mau prognóstico, mas a maioria dos pacientes morre entre o $7^{\circ}$ e $10^{\circ}$ dias de doença devido à falência hepato-renal, ou em decorrência das hemorragias incontroláveis ${ }^{21} 2331$. Os sobreviventes se recuperam lenta, mas completamente e sem seqüelas. Durante a convalescência, a astenia, a indisposição e as dores musculares costumam perdurar por mais de duas semanas ${ }^{21}$.

Doença multi-sistêmica devida à vacinação antiamarílica: recentemente, diversos casos de reação adversa grave seguindo-se à vacinação antiamarílica foram relatados no Brasil ${ }^{59}$, Estados Unidos ${ }^{26} \mathrm{e}$ Austrália $^{8}$. A maioria evoluiu para o óbito.

O quadro clínico revelou-se dramático e caracterizou-se pela infecção multi-sistêmica, generalizada, lembrando as formas graves da febre amarela. Esse quadro manifestou-se nos pacientes 2 a 6 dias após a vacinação. Curiosamente, a idade dos acometidos variou em cada país. No Brasil, os casos registrados $(n=4)$ ocorreram em crianças e adultos jovens (idade variando de 4 a 22 anos, sendo 3 do sexo feminino), e todos morreram após 4 a 6 dias de doença ${ }^{59}$ (Maia ML, dados não publicados); nos Estados Unidos os pacientes eram todos idosos com idade variando entre 63 e 79 anos, dois eram do sexo feminino e apenas um paciente masculino sobreviveu. De um caso isolouse o vírus do sangue e de outro paciente, se detectou antígeno no fígado pela técnica de imunohistoquímica ${ }^{26}$. 
O caso da Austrália, era de um paciente do sexo masculino com 56 anos, que desenvolveu doença dois dias após a vacinação (vacina 17D204) e morreu 7dias depois. Isolouse o vírus do sangue, fígado e múltiplos órgãos ${ }^{8}$.

O quadro histológico e imunohistoquímico dos casos não se diferencia dos casos de febre amarela acometidos pelo vírus selvagem. A necrose no fígado mostrou-se intensa, médio-zonal e acometendo todo o órgão. As lesões no coração sugerem miocardite. O baço também foi acometido. Isolou-se o vírus de todos os tecidos disponíveis, mostrando ser a viremia sistêmica e com alto título ${ }^{59}$.
Os exames bio-moleculares realizados em amostras isoladas em todos os casos brasileiros não evidenciou diferenças genômicas entre as amostras isoladas e a vacina usada, bem como, não se identificou qualquer alteração genômica nas cepas que pudessem justificar a ocorrência dos casos ou sugerir reversão da cepa atenuada para virulenta ${ }^{1759}$.

Atribuiu-se a causa dessas infecções graves e inesperadas à resposta idiossincrática dos indivíduos ${ }^{59}$. Suspeita-se, entretanto, que a explicação para tais casos passam pela herança genética, associada a genes que modulam a resposta imune ao vírus. Esperam-se estudos adicionais para comprovar essa hipótese.

\section{DIAGNÓSTICO}

Exames específicos: o diagnóstico definitivo da febre amarela pode ser feito utilizando-se métodos virológicos (isolamento do vírus em cultura de tecidos) ${ }^{3}$, identificação de antígenos virais ${ }^{19}$ e do RNA viral ${ }^{25}$ e métodos sorológicos - dosagem de anticorpos específicos pelo método de IgM-ELISA que captura anticorpos IgM em ensaio enzimático ${ }^{24}$ ou conversão sorológica em testes de inibição da hemaglutinação ${ }^{3}$. Faz-se o isolamento do vírus em diferentes sistemas: camundongos recém nascidos ou cultivo celular (células VERO, clone C6/36). Após a inoculação da amostra suspeita, obtém-se evidências da replicação viral em torno do $5^{\circ}$ ao $7^{\circ}$ dias de cultura. Ao isolar-se a amostra identifica-se o vírus em testes de imunofluorescência indireta usando-se anticorpos monoclonais ou alternativamente mediante testes de fixação do complemento.

Os métodos sorológicos que identificam IgM específica, como é o caso do IgM-ELISA, podem fornecer o diagnóstico presuntivo rápido em uma amostra sorológica, se a mesma for obtida a partir do $5^{\circ}$ dia de doença. A presença de IgM decorre de infecção recente (2-3 meses) ou corrente (atual), daí porque cumpre-se obter a história clínica completa para a boa interpretação do resultado laboratorial. Vale lembrar que a vacinação anti-amarílica também induz a formação de IgM e, por isso, importa conhecer os antecedentes vacinais do caso suspeito $^{57}$. Quando o paciente sobrevive, comparam-se os resultados sorológicos das amostras aguda e convalescente. Títulos de anticorpos aumentados 4 vezes ou mais na amostra convalescente em comparação aos títulos da amostra da fase aguda, depõem a favor de infecção recente pelo vírus amarílico.

Nos casos fatais em que não se dispõe de sangue para sorologia e a pesquisa de vírus resultou negativa ou prejudicada deve-se procurar antígenos específicos pela técnica de imunohistoquímica em tecidos hepáticos (Figura 8) ou evidenciar o genoma viral por RT-PCR do sangue (células e soro) e fígado ${ }^{59}$. Raramente outros tecidos se mostram positivos. A identificação do genoma viral, quando utilizada com critério, representa opção esclarecedora nos casos indefinidos por má conservação dos espécimens ou nos casos em que os resultados sorológicos permaneceram inconclusivos.

Exames inespecíficos: diversos exames devem ser realizados durante a evolução do quadro de febre amarela. No hemograma, nos primeiros dias da doença, há leucopenia com neutropenia e linfocitose, com valores de 3.000 a 4.000 células por $\mathrm{cm}^{3}$ de sangue. Em alguns casos o leucograma exibe 1.000 a 2.000 leucócitos $/ \mathrm{cm}^{3}$. À medida que o quadro progride se acentua a leucopenia, salvo nos casos em que ocorre infecção bacteriana. Aí, há inversão da tendência e o leucograma fornece contagens de 15.000 a 20.000 leucócitos. A série vermelha usualmente se encontra normal, salvo nos casos com sangramento grave em que há queda do hematócrito e da hemoglobina. As plaquetas usualmente se encontram com valores em torno de $50.000 / \mathrm{cm}^{3}$ de sangue, mas podem apresentar valores ainda menores. Diversos fatores de coagulação são consumidos e quando dosados apresentam-se alterados. Os mais consumidos durante a infecção amarílica são a protrombina, o fator VIII e a tromboplastina. Portanto, os tempos de sangria e de coagulação prolongam-se ${ }^{47}$.

No sumário de urina se observa presença de bilirrubina e de hemácias, mas o que mais chama a atenção é a proteinúria ${ }^{38}$. Não surpreende o encontro de valores de proteína acima de $500 \mathrm{mg} / 100 \mathrm{ml}$ de urina. A densidade medida na urina pode estar alterada.

\section{DIAGNÓSTICO DIFERENCIAL}

Durante os surtos epidêmicos torna-se relativamente fácil diagnosticar a febre amarela, pois, a existência prévia de casos aumenta a suspeita clínica. Fora das epidemias o diagnóstico representa problema. Assim, a abordagem sindrômica se impõe. As enfermidades infecciosas que devem ser incluídas no diagnóstico diferencial são: a malária, as hepatites virais, a febre tifóide, o dengue hemorrágico e as septicemias (Figura 9). Entre as não infecciosas, deve-se lembrar da púrpura trombocitopênica idiopática e algumas formas de envenenamento inclusive a picada de cobras com peçonhas que produzem hemorragias. A história clínica, os antecedentes epidemiológicos e a realização precoce de alguns exames laboratoriais dirime as dúvidas na maioria dos $\operatorname{casos}^{5762}$. 


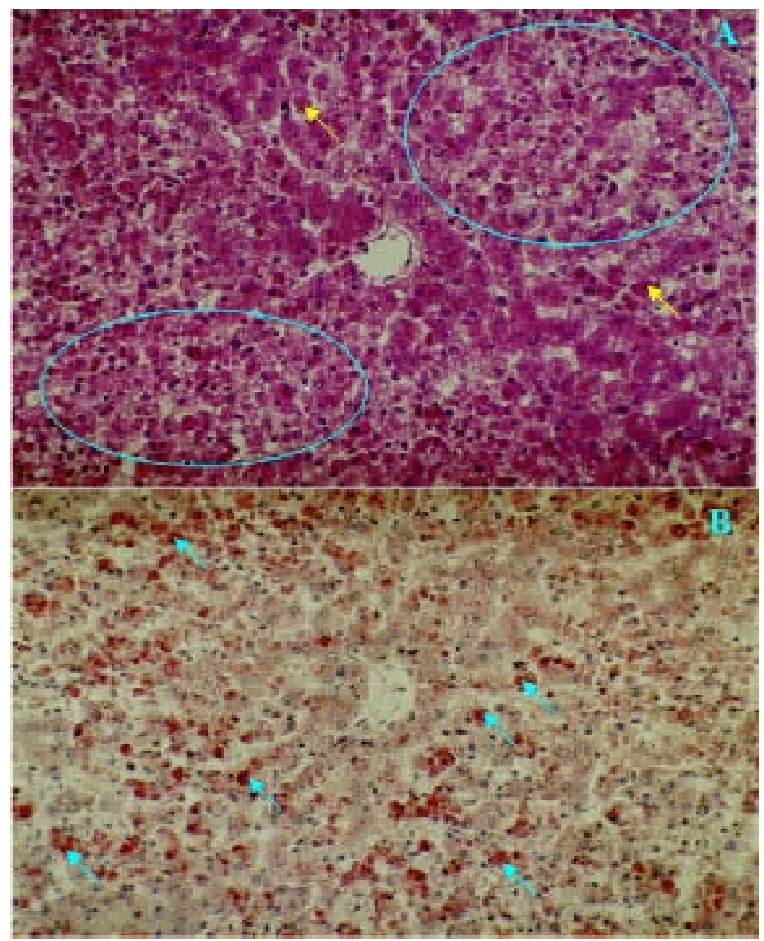

Figura 8 - A) Fígado corado por hematoxilina-eosina, mostrando área peri-portal com necrose (círculos), esteatose e corpusculos de Councilman-Rocha Lima (setas). B) Imunohistoquímica, mostrando os antígenos (setas) corados em vermelho. Ao centro de ambas se vê veia centro cobular (fotografias gentilmente cedidas pela Dra. Vera Barros, Seção de Patologia, Instituto Evandro Chagas).

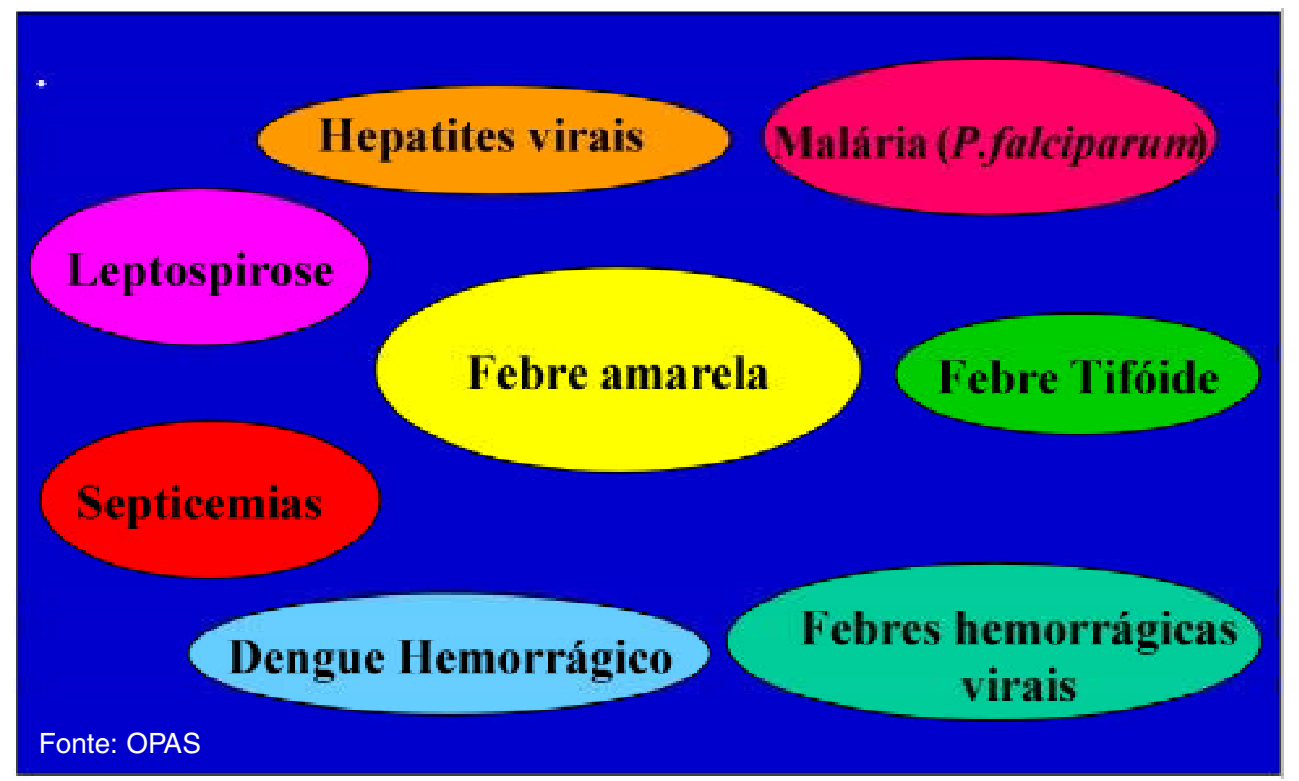

Figura 9 - Diagnóstico diferencial da febre amarela, usando a vigilância sindrômica. 


\section{TRATAMENTO}

Não há medicamento específico para o tratamento da doença. Como os exames diagnósticos da febre amarela demoram em média até uma semana, o tratamento de apoio deve ser iniciado em caso de suspeita clínica dessa virose. Recomenda-se o internamento do paciente com as formas graves em hospitais com boa infra-estrutura e, de preferência, possuidores de unidade de tratamento intensivo (UTI), pois há necessidade de uma série de procedimentos que só se dispõe nessas unidades ${ }^{57}$.

$\mathrm{O}$ tratamento medicamentoso deve se voltar para o combate aos sintomas e os sinais manifestos da doença. Portanto, a medicação a ser prescrita depende das manifestações clínicas, mas é comum o uso de analgésicos e antitérmicos nas doses usualmente indicadas para o peso e a idade. Se contra-indica, entretanto, o uso de medicamentos que contenham em sua fórmula o ácido acetil-salicílico ou seus derivados pois eles podem agravar os fenômenos hemorrágicos. Deve ser prescrito anti-emético para controlar os vômitos, em particular a metoclopramida e também medicamentos para proteger a mucosa gástrica (bloqueadores $\mathrm{H} 2$ ), tais como a cimetidina e a ranitidina ou o omeprazol, pois essas drogas mostram-se úteis para prevenir os sangramentos gástricos, uma das complicações da febre amarela ${ }^{2857}$.

No primeiro sinal de insuficiência renal evidenciada por oligúria, é importante prescrever diuréticos.
A furosemida pode ser usada ou manitol nas doses usuais. A avaliação do paciente deve ser contínua e inclui a verificação dos sinais vitais, da diurese e o acompanhamento diário de pelo menos os seguintes exames: hemograma, plaquetas, fatores de coagulação, sumário de urina e verificação das funções hepática (dosagem das aminotransferases, bilirrubina e gama GT) e renal (dosagem de uréia e creatinina, e monitoramento do balanço hídrico). Nos pacientes com insuficiência renal instalada e rebelde aos diuréticos comuns se indica 0 uso de diálise peritoneal ou hemodiálise ${ }^{57}$.

Não existe critério para a indicação formal de diálise peritoneal. Depende da evolução do paciente. Níveis de creatinina acima de $4 \mathrm{mg} \%$ associado ou não a uréia sérica de $200 \mathrm{mg} \%$ são parâmetros razoáveis ${ }^{57}$. Ressalte-se, entretanto, que é possível indicar hemodiálise com níveis menores se ocorrer anúria. Ou seja, o melhor momento depende do estado geral do paciente, dos valores de creatinina e uréia, da resposta aos diuréticos e da ocorrência ou não de complicações.

Como droga específica, experimentou-se a ribavirina com resultados promissores ${ }^{28}$. Outros estudos são desejáveis. Tratando-se de doença aguda, o tratamento da febre amarela deve ser feito pela via endovenosa. A ribavirina disponível no mercado brasileiro para tratamento da hepatite $\mathrm{C}$ só é oferecida em comprimidos.

\section{PREVENÇÃO}

A febre amarela faz parte da lista de doenças de notificação compulsória e como tal, qualquer caso suspeito deve ser imediatamente notificado à autoridade sanitária local, estadual ou nacional e esta notifica os organismos internacionais. Posteriormente, havendo confirmação laboratorial, a notificação do caso é confirmada e a autoridade nacional ratifica a autoridade sanitária internacional ${ }^{45}$.

O método mais eficaz para se prevenir a febre amarela é a vacinação com a amostra 17D. Atualmente, duas subcepas são usadas na produção de vacinas: 17DD no Brasil e 17D-204 no resto do mundo. A diferença é que a 17DD tem 81 passagens a mais ${ }^{17}$. A OMS recomenda que sejam vacinadas todas as pessoas hígidas com mais de 6 meses de idade que residem nas áreas de risco ou que se dirijam a elas. Uma única dose da vacina protege o indivíduo por pelo menos 10 anos, quando então é recomendada a aplicação de nova vacinação ${ }^{45}$. Abaixo de 6 meses há elevados riscos de desenvolvimento de encefalite pós vacinal ${ }^{20}$.

Como a vacina é produzida com vírus vivo atenuado, não é recomendada a vacinação de pessoas com imunodeficiência face aos riscos de reversão da virulência num hospedeiro com depressão do sistema imune. Portanto, pacientes com SIDA/AIDS, câncer e em uso de medicação imunossupressora não devem ser vacinados, salvo em casos particulares e após cuidadosa avaliação dos riscos e benefícios. Ressaltese, entretanto, que esta recomendação não tem sido avaliada com estudos controlados, e os pacientes vacinados por engano não desenvolveram quadros de febre amarela ${ }^{31}$.

Pessoas com antecedentes de alergia à proteína do ovo também não devem ser vacinadas pelo risco acentuado de desenvolverem reação alérgica do tipo I

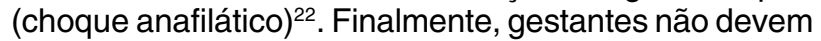
ser vacinadas, considerando o risco de transmissão para o feto. De modo semelhante aos pacientes com imunodepressão, os poucos casos de gestantes vacinadas não desenvolveram infecção grave tampouco seus conceptos. No entanto, sempre que possível, devese evitar a vacinação desses grupos ${ }^{36} 4454$.

Outro procedimento que pode prevenir a ocorrência da febre amarela é o combate aos vetores e o uso de medidas de proteção individual. O combate aos vetores silvestres é inviável. Resta o combate ao vetor urbano, Aedes aegypti, que tem sido tentado desde o início do século com sucessos e fracassos. Hoje, com a complexidade das áreas urbanas, elevada concentração populacional e aumento da pobreza, bem como o agravamento do problema com o lixo urbano e a deficiência no fornecimento de água, torna-se muito difícil viabilizar a curto e médio prazos a eliminação ou mesmo o efetivo controle do Aedes aegypti em todo o 
continente americano em níveis que impeçam a ocorrência de epidemias urbanas de febre amarela.

Por outro lado, vale assinalar que nas últimas epidemias urbanas de febre amarela ocorridas na África, os índices de infestação têm sido extremamente elevados, com valores acima de $50 \%$, a ponto de se questionar a competência vetorial do Aedes aegypti ${ }^{27}$. Tal fato não se verifica no Brasil, onde os índices têm se mantido baixos, raramente atingindo $10 \%{ }^{16}$. Medidas de proteção individual como o uso de repelentes e de mosquiteiros carecem de importância em saúde pública.

Risco de urbanização: desde os anos 80 e com maior evidência nos anos 90 , tem se verificado a reemergência da febre amarela em termos de número de casos, tanto na África como na América. No Novo Mundo, dezenas e freqüentemente centenas de casos são anualmente notificados. Na América, mais de $90 \%$ dos casos descritos nas décadas de 70-90 ocorreram no Peru, na Bolívia e no Brasil. O Brasil é o terceiro país que notifica febre amarela nas Américas com cerca de 19\% dos casos. Esta emergência tem ocorrido simultaneamente com o incremento na dispersão do Aedes aegypti e epidemias de dengue ${ }^{12} 33606368$, o que aumenta o risco de reurbanização (Figura 10).

No Brasil, todos os anos, a doença tem sido diagnosticada. Na década de 1970, o estado mais
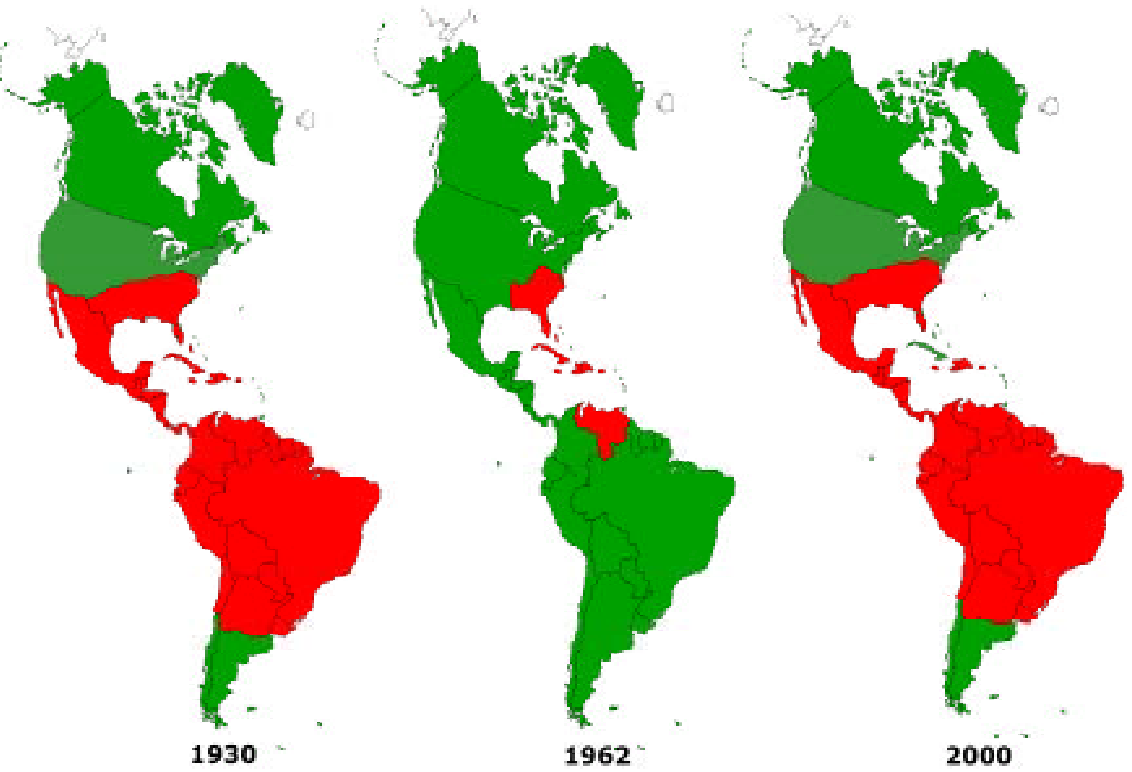

Figura 10 - Distribuição do Aedes aegypti nas Américas: 1930, 1962 e 2000. Fonte: OPAS/OMS.

atingido foi Goiás ${ }^{40} 41$. Nos anos 80 , lideram as estatísticas o Pará62 e o Mato Grosso do Sul ${ }^{11}$. Nos Anos 90, novamente o Pará e o Maranhão foram os mais acometidos $^{6064}$. Em 2000, Goiás ${ }^{58}$ voltou a ser o mais atingido e em 2001, Minas Gerais notificou a maioria dos casos $^{6}$. Todos os casos decorreram de transmissão silvestre. Cerca de $90 \%$ dos casos encontram-se associados com a transmissão pelo Hg Janthinomys. Mais de $80 \%$ ocorreram em adolescentes e adultos jovens do sexo masculino e a letalidade tem variado muito (média de 50\%), o que se deve à falha no reconhecimento e no diagnóstico das formas leve e moderada e de assintomáticos ${ }^{57}$. Ressalte-se que no passado não havia preocupação em se fazer busca ativa dessas formas atípicas, o que limitava o número de casos diagnosticados. Sabe-se agora que esses casos representam importante fonte de infecção para os mosquitos transmissores e que os infectados desenvolvem viremia em níveis suficientes para infectar os vetores.

Até o início dos anos 90 apenas o IEC (no Pará) realizava o diagnóstico da doença na área endêmica. Hoje há laboratórios realizando o diagnóstico no Acre, Amapá, Amazonas, Distrito Federal, Goiás, Mato Grosso, Mato Grosso do Sul, Minas Gerais, Tocantins, Roraima, São Paulo e Rio de Janeiro. Houve, portanto, melhora sensível da capacidade laboratorial o que agiliza a vigilância epidemiológica. Também as técnicas diagnósticas melhoraram muito, com a introdução da imunohistoquímica e RT-PCR que vieram complementar as técnicas de isolamento viral e sorologia (especialmente a identificação de IgM pelo ensaio imunoenzimático). 
Por outro lado, o Aedes. aegypti encontra-se distribuído em todos os estados do país, tanto dentro como fora da área endêmica. Urge estudar o papel do Aedes aegypti no Brasil (recomenda-se manipulação em laboratórios com condições de segurança, devido ao atual estado de disseminação do vetor urbano) para se conhecer sua susceptibilidade, sensibilidade e capacidade de transmitir o virus da febre amarela. Em outras palavras, não se sabe a real capacidade vetorial da população de Aedes aegypti que circula no Brasil.

A cobertura vacinal anti-amarílica varia de acordo com a área, sendo boa nas áreas endêmicas e de transição (cobertura geral acima de $80 \%$ ) e ruim na área indene da doença. Excetuando os estados de São Paulo (abandonado a partir dos casos vacinais) e Paraná que adotaram programas de vacinação sistemática de toda a população é provável que no máximo $20 \%$ da população esteja vacinada. Em números teríamos cerca de 7 a 8 milhões de pessoas não vacinadas em áreas endêmicas e epizoóticas, principalmente nas capitais, e algo como 70 a 100 milhões na área indene ${ }^{16}$. Na figura abaixo se observa as doses aplicadas de vacina contra a febre amarela no Brasil, no período de 1990 a 2000. Nota-se o crescimento espetacular na vacinação anti-amarílica (Figura 11).
Diante desses dados, torna-se necessário: (1) procurar vacinar toda a população nas capitais das áreas endêmicas e de transição e avaliar a possibilidade de vacinar os habitantes dos núcleos urbanos da área indene; (2) implantar a vigilância sindrômica (ou seja, realizar exames nos quadros infecciosos agudos que cursam com febre, hemorragia, icterícia e insuficiência renal) em maior número de estados, o que resultará em melhora da vigilância epidemiológica por se tornar mais sensível; (3) nos casos de suspeita clínica e/ ou epidemiológica de caso(s) deve-se atuar simultaneamente na colheita de amostras de contatos e familiares e também de outros casos suspeitos e aplicar a vacinação de bloqueio para abortar a transmissão; (4) continuar a descentralização do diagnóstico para agilizar as ações de prevenção e controle; (5) diminuir os índices de infestação do Aedes aegypti nos grandes núcleos urbanos de todo o país (medida que também diminuirá a ocorrência de dengue); (6) realizar estudos para estabelecer a capacidade vetorial da população circulante de Aedes aegypti e; (7) treinar e reciclar os clínicos no reconhecimento da doença, o que elevará o índice de suspeita da febre amarela e, consequentemente, dos casos diagnosticados.

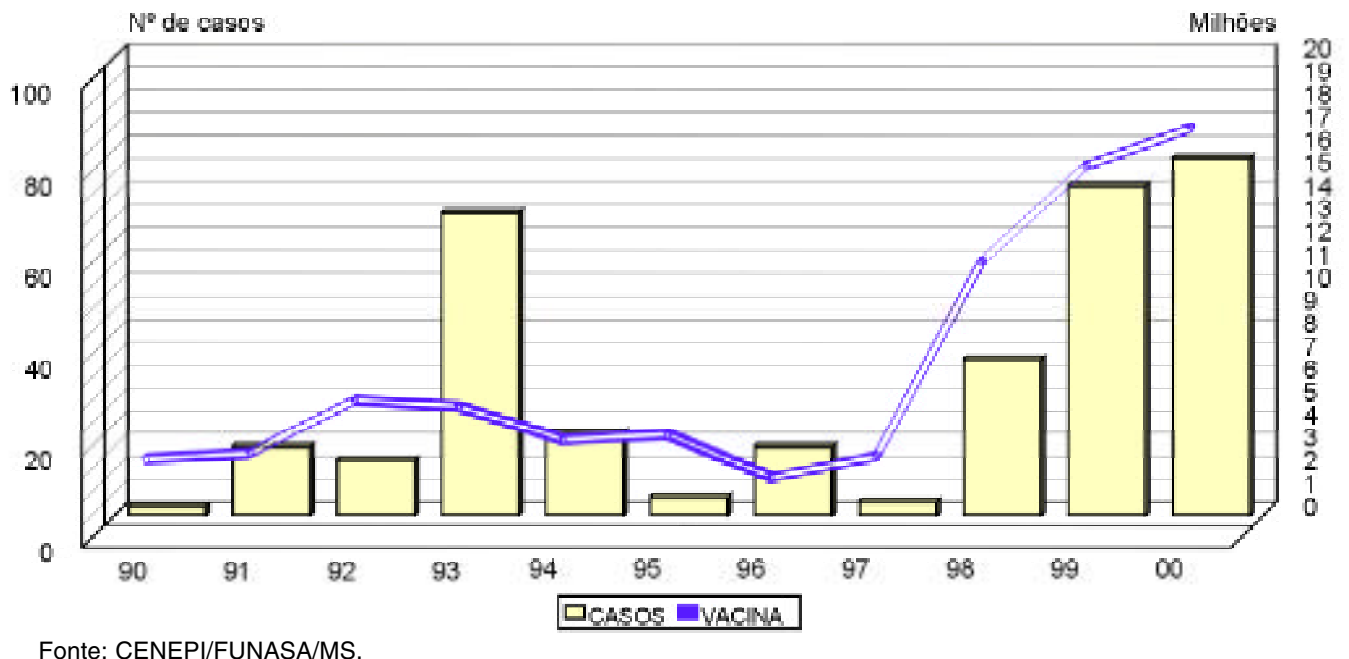

Figura 11 - Casos de febre amarela e doses de vacinas aplicadas no Brasil, 1990-2000.

Se esses pontos forem adotados, e vale ressaltar que o governo federal adotou diversas medidas nesse sentido, através do Plano de Intensificação do Controle da Febre Amarela ${ }^{16}$, não há dúvida de que a febre amarela ficará restrita às fortuitas ocorrências anuais com reduzido número de casos, praticamente eliminando o risco de reurbanização.

Devemos ter em mente que o risco de adoecer permanece. Novos casos de febre amarela serão diagnosticados anualmente, pois a necessidade de invadir as matas em busca de recursos naturais continuará, mas, a ingenuidade e a ignorância das pessoas favorecem o vírus. Portanto, cumpre melhorar a vigilância principalmente nos municípios e estados, ou seja, permaneça alerta, suspeitando da doença. Procure educar e reciclar melhor o pessoal de saúde, vacinar as populações suscetíveis e estudar as epidemias. Assim aumenta-se o conhecimento acerca da história natural da doença e evita-se o retorno de outro flagelo que já mostrou o seu poder destruidor na história médica do Brasil. 


\section{AGRADECIMENTOS}

Agradecimentos são devidos à FUNASA aos Drs. Eduardo Hage Carmo, Maria de Lourdes Maia e Zouraide Guerra Costa; OPAS ao Dr. Otávio Oliva; e IRD ao Dr. Nicolas Dégallier por cederem dados não publicados e incluídos nessa revisão.

\section{REFERÊNCIAS BIBLIOGRÁFICAS}

1. Barrett ADT. Yellow fever vaccines. Biologicals 25:17-25, 1997.

2. Bearcroft WGC. The histopathology of the liver of yellow feverinfected Rhesus monkeys. Journal Pathology of Bacteriology 74:295-303, 1957.

3. Beaty B, Calisher $\mathrm{CH}$, Shope RE. Arboviruses. In: Schmidt NJ, Emmons RW (eds) Diagnostic Procedures for Viral, Rickettsial and Chlamydial Infections, $6^{\text {th }}$ edition. American Public Health Association, Washington, p. 797-855, 1989.

4. Benchimol JL. Febre amarela: A doença e a vacina, uma história inacabada. Editora FIOCRUZ, Rio de Janeiro, 2001.

5. Brés PLJ. A century of progress in combating yellow fever. Bulletin of the World Health Organization 64:775-786, 1986.

6. Carmo EH, Martins E, Pelucci HH, Maia ML, Duzzi R, Tuboi S, Costa ZG. Brote de fiebre amarilla selvática en Minas Gerais, Brasil. Boletin Informativo PAl, Organización Pan-Americana de la Salud, Washington, 24:5-6, 2002.

7. Chambers TJ, Hahn CS, Galler R, Rice CM. Flavivirus genome organization, expression, and replication. Annual Reviews of Microbiology 44:649-488, 1990.

8. Chan RC, Penney DJ, Little D, Carter IW, Roberts JA, Rawlinson WD. Hepatitis and death following vaccination with 17D-204 yellow fever vaccine. Lancet 358:121-122, 2001.

09. Costa ZGA, Oliveira RC, Tuboi SH, Silva MM, Vasconcelos PFC. Redefinição das áreas de risco para febre amarela silvestre no Brasil. Revista da Sociedade Brasileira de Medicina Tropical 35 (supl I): 84, 2002.

10. Dégallier N, Travassos da Rosa APA, Hervé JP, Travassos da Rosa JFS, Vasconcelos PFC, Mangabeira da Silva CJ, Barros VLRS, Dias LB, Travassos da Rosa ES, Rodrigues SG. A comparative study of yellow fever in Africa and South America. Brazilian Journal of the Association for Advancement of Science 44:143-161, 1992a.

11. Dégallier N, Travassos da Rosa APA, Vasconcelos PFC, Travassos da Rosa ES, Rodrigues SG, Sá Filho GC, Travassos da Rosa JFS. New entomological and virological data on the vectors of sylvatic yellow fever in Brazil. Brazilian Journal of the Association for Advancement of Science 44:136-142, 1992b.

12. Dégallier N, Travassos da Rosa APA, Vasconcelos PFC, Figueiredo LTM, Travassos da Rosa JFS, Rodrigues SG, Travassos da Rosa ES. La dengue et ses vecteurs au Brésil. Bulletin de la Société de Pathologie Exotique 89:128-136, 1996.

13. Digoutte JP, Cornet M, Deubel V, Downs WG. Yellow fever. In: Porterfield JS (ed) Exotic Viral Infections, Chapman + Hall Medical, London, p. 67-102, 1995.

14. Dutary BE, Leduc JW. Transovarial transmission of yellow fever virus by a sylvatic vector. Transactions of the Royal Society of Tropical Medicine and Hygiene 75:128, 1981.

15. Franco O. História da febre amarela no Brasil. Departamento Nacional de Endemias Rurais, Ministério da Saúde, Rio de Janeiro, 1969.
16. Fundação Nacional de Saúde. Plano de Intensificação de controle da febre amarela no Brasil. Fundação Nacional de Saúde, Basília (Mimeografado), 2001.

17. Galler R, Pugachev KV, Santos CLS, Ochran SW, Jabor AV, Rodrigues SG, Marchevsky RS, Freire MS, Almeida LFC, Cruz ACR, Yamamura AMY, Rocco IM, Rosa EST, Souza LTM, Vasconcelos PFC, Guirakhoo F, Monath TP. Phenotypic and molecular analyses of yellow fever 17DD vaccine viruses associated with serious adverse events in Brazil. Virology 290:309-319, 2001.

18. Groot H, Bahia-Ribeiro R. Neutralizing and haemagglutinationinhibiting antibodies to yellow fever 17 years after vaccination with 17D vaccine. Bulletin of the World Health Organization 27:699-707, 1962.

19. Hall WC, Crowell TP, Watts DM, Barros VLR, Kruger H, Pinheiro FP, Peters CJ. Demonstration of yellow fever and dengue antigens in formalin-fixed paraffin-embedded human liver by immunohistochemical analysis. American Journal of Tropical Medicine and Hygiene 45:408-17, 1991.

20. Jennings $A D$, Gibson $C A$, Miller BR, Matthews JH, Mitchell CJ, Roehrig JT, Wood DJ, Taffs F, Sil BK, Whitby SN, Minor PD, Monath TP, Barrett ADT. Analysis of a yellow fever virus isolated from a fatal case of vaccine-associated human encephalitis. Journal of Infectious Diseases 169:512-518, 1994.

21. Jones EMM, Wilson DC. Clinical features of yellow fever cases at Vom Christian Hospital during the 1969 epidemic on the Jos Plateau, Nigeria. Bulletin of the World Health Organization 46:653657, 1972.

22. Kelso JM, Mootrey GT, Tsai TS. Anaphylaxis from yellow fever vaccine. Journal of Allergy Clinical and Immunology 103: 698-701, 1999.

23. Kerr JA. The clinical aspects and diagnosis of yellow fever. In: Strode GK (ed) Yellow fever, McGraw-Hill, New York, p. 385-425,1951.

24. Kuno G, Gomez I, Gubler DJ. Detecting artificial antidengue IgM complexes using a enzyme linked immunosorbent assay. American Journal of Tropical Medicine and Hygiene 36:153-159, 1987.

25. Lanciotti RS, Calisher CH, Gubler DJ, Chang G-J, Vorndam V. Rapid detection and typing of dengue viruses from clinical samples by using reverse transcriptase-polymerase chain reaction. Journal of Clinical Microbiology 30:545-551, 1992.

26. Martin M, Tsai TF, Cropp B, Chang GJJ, Holmes DA, Tseng J, Shieh WJ, Zaki SR, Al-Sanouri I, Cutrona AF, Ray G, Weld LH, Cetron MS. Fever and multisystem organ failure associated with 17D-204 yellow fever vaccination: a report of four cases. Lancet 358:98-104, 2001.

27. Miller BR, Monath TP, Tabachnick WJ, Ezike VI. Epidemic yellow fever caused by an incompetent mosquito vector. Tropical Medicine and Parasitology 40:396-399, 1989.

28. Monath TP.Yellow fever: a medically neglected infectious disease. Reviews of Infectious Diseases 9:165-175, 1987. 
29. Monath TP. Yellow fever. In: Monath TP (ed) Arboviruses: ecology and epidemiology, Volume. V, CRC Press, Boca Raton, p.139241, 1988.

30. Monath TP. Epidemiology of yellow fever: current status and speculations on future trends, Saluzzo JF, Dodet B (ed). In: Factors in the Emergence of Arbovirus Diseases, Elsevier, Paris, p. 143-156, 1997.

31. Monath TP. Yellow fever: An update. Lancet Infectious Diseases 1:11-20, 2001.

32. Monath TP, Brinker KR, Chandler FW, Kemp GE, Cropp CB. Pathophysiologic correlations in a rhesus monkey model of yellow fever: with special observations on the acute necrosis of $B$ cell areas of lymphoid tissues. American Journal of Tropical Medicine and Hygiene 30:431-443, 1981.

33. Mondet B, Travassos da Rosa APA, Vasconcelos PFC. Les risques d'épidémisation urbaine de la fièvre jaune au Brésil Aedes aegypti et Aedes albopictus. Bulletin de la Société de Pathologie Exotique 89:107-114, 1996.

34. Mondet B, Vasconcelos PFC, Travassos da Rosa APA, Travassos da Rosa ES, Rodrigues SG, Travassos da Rosa JFS, Bicout DJ. Isolation of Yellow Fever Virus from Nulliparous Haemagogus (Haemagogus) janthinomys in Eastern Amazonia. Vectorborne and Zoonotic Diseases 2: 47-50, 2002.

35. Mutebi JP, Wang H, Li L, Bryant JE, Barrett ADT. Phylogenetic and evolutionary relationships among yellow fever virus isolates in Africa. Journal of Virology 75:6999-7008, 2001.

36. Nasidi A, Monath TP, Vanderberg J. Yellow fever vaccination and pregnancy: a four-year prospective study. Transactions of the Royal Society of Tropical Medicine and Hygiene 87:337-339, 1993.

37. Nobre A, Antezana D, Tauil PL. Febre amarela e dengue no Brasil: epidemiologia e controle. Revista da Sociedade Brasileira de Medicina Tropical 27 (supl III):59-66, 1994.

38. Oudart JL, Rey M. Protéinurie, protéinémie et transaminasémies dans 23 cas de fievre jaune confirmée. Bulletin of the World Health Organization 42:95-101, 1970.

39. Pan American Health Organization - PAHO. Casos y muertes por fiebre amarilla en región de las Américas. Pan American Health Organization, Washington, 2002.

40. Pinheiro FP, Moraes MAP. Febre amarela. In: Neves J (ed.) Diagnóstico e tratamento das doenças infectuosas e parasitárias, $2^{\mathrm{a}}$ ed, Editora Guanabara-Koogan, Rio de Janeiro, p. 303314,1983 .

41. Pinheiro FP, Travassos da Rosa APA, Moraes MAP, Neto JCA, Camargo S, Filgueiras FP. An epidemic of yellow fever in central Brazil, 1972-1973. I. Epidemiological studies. American Journal of Tropical Medicine and Hygiene 27:125-132, 1978.

42. Poland JD, Calisher $\mathrm{CH}$, Monath TP, Downs WG, Murphy K. Persistence of neutralizing antibody 30-35 years after immunization with 17D yellow fever vaccine. Bulletin of World Health Organization 59:895-900, 1981.

43. Rice CM, Lenches EM, Eddy SR, Shin SH, Strauss JH. Nucleotide sequence of yellow fever virus: implications for flavivirus gene expression and evolution. Science 229:726-733, 1985.

44. Robert E, Vial T, Schaefer C, Arnon J, Reuvers M. Exposure to yellow fever vaccine in early pregnancy. Vaccine 17:283-285, 1999.
45. Robertson SE. The immunological basis for immunization series: Yellow fever. World Health Organization (Document WHO/EPI/ GEN/93.18), Geneva, 1993.

46. Robertson SE, Hull BP, Tomori O, Bele O, LeDuc JW, Esteves K. Yellow Fever. A decade of reemergence. Journal of the American Medical Association 276:1157-1162, 1996.

47. Santos F. Dosagem dos fatores da coagulação na febre amarela. Tese de Doutorado, Universidade Federal do Rio de Janeiro, Rio de Janeiro, 1973.

48. Serié C, Lindrec A, Poirier A, Andral L, Neri P. Etudes sur la fievre jaune em Ethiopie. I. Introduction et simptomatologie clinique. Bulletin of the World Health Organization 38:835-841, 1968.

49. Soper FL. Jungle yellow fever: new epidemiological entity in South America. Revista de Hygiene e Saúde Pública 10:107-144, 1936.

50. Strode GK. Yellow fever. New York: McGraw-Hill, 1951.

51. Taylor RM. Epidemiology. In: Strode GK (ed) Yellow fever. McGrawHill, New York, p. 427-459, 1951.

52. Tesh RB, Guzman H, Travassos da Rosa APA, Vasconcelos PFC, Dias LB, Bunnell JE, Zhang H, Xiao SY. Experimental yellow fever virus infection in the Golden Hamster (Mesocricetus auratus). 1. Virologic, Biochemical and Immunologic studies. Journal of Infectious Diseases 183:1431-1436, 2001

53. Tigertt WD, Berge TO, Gochenour WS, Gleiser CA, Eveland WC, Bruegge CV, Smetana HF. Experimental yellow fever. Transactions of the New York Academy of Science 22:323-333, 1960.

54. Tsai TF, Paul R, Lynberg MC, Letson GW. Congenital yellow fever virus infection after immunization in pregnancy. Journal of Infectious Diseases 168:1520-1523, 1993.

55. Van der Stuyft P, Gianella A, Pirard M, Cespedes J, Lora J, Peredo C, Pelegrino JL, Vorndam V, Boelaert M. Urbanisation of yellow fever in Santa Cruz, Bolivia. Lancet 353:1558-1562, 1999.

56. Vanio J, Cutts F. Yellow fever. World Health Organization. Document WHO/EPI/GEN/18.11, Geneva, 1998.

57. Vasconcelos PFC. Febre amarela. Sociedade Brasileira de Pediatria, Rio de Janeiro, 2000.

58. Vasconcelos PFC, Costa ZG, Travassos da Rosa ES, Luna E, Rodrigues SG, Barros VLRS, Dias JP, Monteiro HAO, Oliva OFP, Vasconcelos HB, Oliveira RC, Sousa MRS, Barbosa da Silva J, Cruz ACR, Martins EC, Travassos da Rosa JFS. An epidemic of jungle Yellow fever in Brazil, 2000. Implications of climatic alterations in disease spread. Journal of Medical Virology 65:598-604, 2001.

59. Vasconcelos PFC, Luna EJ, Galler R, Silva LJ, Coimbra TL, Barros VLR, Monath TP, Rodrigues SG, Laval C, Costa ZG, Vilela MFG, Santos CLS, Papaiordanou CM, Alves VAF, Andrade LD, Sato HK, Rosa EST, Froguas GB, Lacava E, Almeida LMR, Cruz ACR, Rocco IM, Santos RTM, Oliva OFP. Serious adverse events associated with yellow fever 17DD vaccine in Brazil: Report of two cases. Lancet 358:91-97, 2001.

60. Vasconcelos PFC, Rodrigues SG, Dégallier N, Moraes MAP, Travassos da Rosa JFS, Travassos da Rosa ES, Mondet B, Barros VLRS, Travassos da Rosa APA. An epidemic of sylvatic yellow fever in the southeast region of Maranhão State, Brazil, 19931994: epidemiologic and entomologic findings. American Journal of Tropical Medicine and Hygiene 57:132-137, 1997.

61. Vasconcelos PFC, Sperb AF, Monteiro HAO, Torres MAN, Souza MRS, Vasconcelos HB, Mardini LBLF, Rodrigues SG. Isolations of yellow fever virus from Haemagogus leucocelaenus in Rio 
Grande do Sul State, Brazil, in the Southern Cone. Transactions of the Royal Society of Tropical Medicine and Hygiene 97, 2003.

62. Vasconcelos PFC, Travassos da Rosa APA, Pinheiro FP, Dégallier N, Travassos da Rosa JFS. Febre amarela. In: Leão RNQ (ed) Doenças Infecciosas e Parasitárias. Enfoque Amazônico. Editora CEJUP, Belém, p. 265-284,1997.

63. Vasconcelos PFC, Travassos da Rosa APA, Pinheiro FP, Rodrigues SG, Travassos da Rosa ES, Cruz ACR, Travassos da Rosa JFS. Aedes aegypti, dengue and re-urbanization of yellow fever in Brazil and other South American Countries - Past and present situation and future perspectives. World Health Organization, Dengue Bulletin (New Delhi) 23:55-66, 1999.

64. Vasconcelos PFC, Travassos da Rosa APA, Rodrigues SG, Travassos da Rosa ES, Monteiro HAO, Cruz ACR, Barros VLR, Souza MRS, Travassos da Rosa JFS. Yellow fever in Pará State, Amazon Region of Brazil, 1998-1999. Entomologic and epidemiologic findings. Emerging Infectious Disease 7:565-569, 2001.
65. Wang E, Weaver SC, Shope RE, Tesh RB, Watts DM, Barrett ADT. Genetic variation in yellow fever virus: duplication in the 3 ' noncoding region of strains from Africa. Virology 225:274-281, 1996.

66. Westaway EG, Briton MA, Gaidamovich SY, Horzinek MC, Igarashi A, Kaariainen L, Lvov DK, Porterfield JL, Russell PK, Trent DW. Flaviviridae. Intervirology 24:183-192, 1985.

67. World Health Organization. Prevention and control of yellow fever in Africa, Geneva, 1985.

68. World Health Organization. Dengue haemorrhagic fever: diagnosis, treatment and control $2^{\text {nd }}$ edition. World Health Organization, Geneva, 1997.

69. Xiao SY, Zhang H, Guzman H, Tesh RB. Experimental yellow fever virus infection in the Golden Hamster (Mesocricetus auratus). 2. Pathology. Journal of Infectious Diseases, 183:1437-1444, 2001.

70. Zanotto PMA, Gould EA, Gao GF, Harvey PH, Holmes EC. Population dynamics of flaviviruses revealed by molecular phylogenies. Proceedings of the National Academy of Sciences 93:548-553, 1996 